\title{
Progressive Recovery of a Marine Gastropod Community Following Atmospheric Nuclear Tests in French- Polynesia: A Socio-ecological Interpretation
}

\author{
Jean Béguinot ${ }^{1 *}$ \\ ${ }^{1}$ Université de Bourgogne, 6, Boulevard Gabriel, 21000 Dijon, France.
}

Author's contribution

The sole author designed, analysed, interpreted and prepared the manuscript.

Article Information

DOI: 10.9734/ARRB/2021/v36i130335

Editor(s):

(1) Dr. Md. Aminur Rahman, Jashore University of Science and Technology, Bangladesh.

Reviewers:

(1) Oguh Collins Egwu, Nigeria Centre for Disease Control, Nigeria. (2) Awé Djongmo Victor, University of Ngaoundere, Cameroon. Complete Peer review History: http://www.sdiarticle4.com/review-history/66275

Original Research Article

Received 02 January 2021

Accepted 03 March 2021

Published 16 March 2021

\begin{abstract}
Aims: The way species-richness is accommodated and how species-abundance distribution is organized in a hierarchic pattern is central to community ecology. Yet, the process by which species-richness and species-abundances are progressively accommodated can hardly be monitored, in practice, at a sufficiently large spatial scale. Fortunately, the progressive recovery of marine communities, after their complete destruction by atmospheric nuclear tests, yet offered unique opportunity to monitor the full process of accommodation of increasing species-richness and the associated, transient development of strong interspecific competition, all along the process of recovery.

Methods: Taking full advantage of such monitoring yet requires, first, to relevantly overcome two important practical issues: 1) achieving reliable numerical extrapolations of the usually unavoidably incomplete samplings in order to accurately estimate both the true species-richness and the completed distribution of species-abundances, including the abundance of undetected species and 2) disentangling (i) the positive contribution of improved niche-diversification to species-richness and species-abundance evenness from (ii) the negative contribution of increasing interspecificcompetition, all along the recovery progress. This, indeed, is a rather tricky challenge, yet relevantly solved by using the newly developed "standardized unevenness index", conceptually based upon MacArthur approach to interspecific-contest at niche overlaps.
\end{abstract}


Results: Applying both tools above to the monitored recovery of a reef-associated Gastropod community, entirely wiped-out previously by severe nuclear blasts, had allowed a deeper understanding of the dynamic interplay between species-recruitment, niche-diversification and interspecific-competition in the regeneration of the community. In particular, along the recovery process, a transient, metastable phase - involving severe interspecific-competition at niche-overlaps - precedes a gradual return to dynamic stability, with the virtual extinction of interspecific competition

Keywords: Resilience; species-richness; evenness; niche-diversification; resource-partitioning; nicheoverlap; interspecific competition, Fangataufa atoll.

\section{INTRODUCTION}

Understanding how species organization within natural species assemblages progressively arises and maintains is one of the major focal issues in community ecology [1-3]. And beyond species composition and the overall density of individuals, it is by considering and analyzing in detail the (complete) distribution of species abundances that it becomes possible to get deeper enlightenment on how proceeds the organization of species within communities [4]. In practice, two quantitative aspects of the distribution of species abundances are generally considered to synthetize the main features of this distribution of species abundances: the total number of co-occurring species and how uneven are their abundances. The abundance unevenness reflecting, synthetically, the outcome of the complex and intricate relationships that cooccurring species establish with (i) the local environment (abiotic constraints) and (ii) between them all (biotic relationships, especially competitive interactions). The (total) species richness and the degree of unevenness of species abundances thus feature as the two major quantitative guides which will aptly serve, not only as synthetic descriptors of species organization but, still more importantly, as convenient tools to interpret the origin of this organization and, in particular, to disentangle the ecological drivers involved therein.

Considering now the practical issues arising from this approach, the emphasis put, above, on the notions of "total" species richness and "complete" distribution of species abundances simply means that these two parameters, central for the description of species internal organization, should imperatively be derived from exhaustive field data, as far as possible. Exhaustivity being reached by either:

(i) conducting sampling of the studied community in order to reach full completeness, (ii) or, if this reveal being impossible to achieve in practice - as is often the case for speciose communities - by implementing an appropriate numerical extrapolation of the incompletely achieved sampling, a procedure which now becomes easily practicable for estimating, not only the species richness but also the respective abundances of each of the undetected species [5-7].

Now, once species richness and abundance unevenness have been derived from exhaustive field data or reliable numerical extrapolation, a major objective of community ecology can be approached, namely: how these two fundamental factors are accommodated (i) at first, progressively during the natural establishment of a community and (ii) ultimately, when the community is expected to have reached some apparent or real equilibrium stage. In particular, two interrelated factors deserve special consideration:

- $\quad$ the improved niche-diversification thereby favoring both species-abundance evenness and species-richness accommodation ("species packing");

- $\quad$ the increased degree of niches (functional) overlaps, which may arise from niches overcrowding resulting from nichediversification being insufficient to accommodate efficiently the recruited species-richness, thereby disfavoring both species-abundance evenness and species-richness accommodation.

Thus, of prime importance is trying to uncover the balance between these two related aspects niche-diversification and niche-overlapping - and their opposite influences (respectively positive and negative) on both species-accommodation, and abundance-evenness. And, finally, on the resulting stability of species-richness (as far as species-richness stability is an expected 
outcome of improved species evenness). Since, it is likely, that this subtle balance may substantially differ among natural communities even when communities happen to share the same level of species-richness. Hence the interest of multiplying case-studies in this respect.

The subject is, indeed, of both speculative and practical interests.

Speculative interest, since a deeper understanding of the processes involved in the accommodation of both species-richness and species-abundance unevenness will cast more light upon how species communities are internally structured, in particular in term of the establishment of the hierarchic distribution of abundances among co-occurring species.

Practical interest, because gaining a better knowledge upon all those factors which either can help stabilize or, on the contrary, contribute to destabilize the level of speciesrichness within communities is of obvious major concern, in particular for conservation biologists.

And, in this respect, it is important to disentangle the respective roles of (i) internal processes acting within the community (in particular, the role of interspecific competition, likely elicited when the number of recruited species markedly exceeds what may be ideally accommodated by niche-diversification) from (ii) the direct influence of external drivers (i.e. environmental factors, dispersal capacity, etc ...), since both can affect the level of accommodated species-richness and its expected long-term stability.

In practice, among those case studies, called above to fuel the analysis in this respect, the monitoring of the progressive recovery of a community, following its brutal destruction, features of major interest. In this perspective, nuclear experimental tests, conducted around the mid-twentieth century, directly above marine invertebrate communities, in some remote islets of the central Pacific Ocean, offer attractive opportunities to follow such a radical recovery after complete destruction.

Hereafter is proposed an ecological analysis of such a case study, based on the reported restoration of a reef-dwelling gastropod community after a drastically destructive series of atmospheric nuclear tests conducted on Fangataufa atoll (French Polynesia) [8,9].

\section{GENERAL CONSIDERATIONS}

It is largely admitted that the accommodation of species richness within community essentially proceeds by a sufficient "diversification" of niches, offering sufficient resource partitioning to the co-occurring species, in order to avoid excessive contest for shared resource among the latter [10-18], thus allowing improved species "packing" [3,19-21]. Quoting [18]: "in species-rich areas, biotic interactions drive species to specialize" thereby adapting to more finely diversified resource allocations (i.e. improved resource partitioning).

Yet, most often, "ideal" niche diversification is not actually reached, letting subsist more or less extended niche-overlaps - more precisely "functional" (i.e. inducing interspecific contests) overlaps between more or less intersecting niches: see Appendix 1. Thus, it is worth examining to what extent interspecific competition for partially shared resource subsists or, even, is promoted during the accommodation process of an increasing number of recruited species, thereby involving the occupation of increasingly numerous niches. And this, especially, if the overall density in individuals actually encourages interspecific contests for shared resources at niches overlaps.

Beyond speculative interest, the issue is also of practical concern because, admittedly, stronger interspecific competition would likely induce a severe decrease in the relative abundance of the rarest species. Which in turn, would put these rarest species at risk of local extinction, thereby threatening the stability of species richness itself. Indeed, rarest species are especially prone to being dislodged by other, more competitive species, either already present or new coming [22]. Moreover, would these rarer species escape competitive elimination, their substantially decreasing abundance may ultimately fall under the fatal threshold of "Allee effects", leading to their local extinction $[23,24]$.

\section{MATERIALS AND METHODS}

\subsection{The Reported Field Data}

The present study is based on the reported recovery of a reef-associated gastropod community on Fangataufa, a small atoll located in mid-Pacific Ocean (Tuamotu Archipelago, French Polynesia) subjected to atmospheric nuclear testing between the end of 1968 and 
$1970[8,9]$. The monitored community was more precisely located on the reef flat and edge at 'Terme-Sud' of the Fangataufa atoll [precise location: $\left.22^{\circ} 16^{\prime} 30^{\prime \prime} S, 138^{\circ} 44^{\prime} 48^{\prime \prime} \mathrm{W}\right]$. All additional details regarding the precise location of the community and the sampling procedure are provided in the open-access references $[8,9]$ and need not being further repeated here. Six samplings were conducted, the first one in 1968, before the first test, the five following samplings after the series of tests, in 1972, 1974, 1977, 1987, 1997. Apart from the first sampling, all other samplings, from 1972 to 1997, revealed being slightly $(1972,1987,1997)$ to more strongly incomplete $(1974,1977)$, as will be shown below in Table 1.

As (sub-)exhaustive inventories are required to avoid making biased inferences regarding the main structural descriptors of ecological communities (in particular, the total speciesrichness and the abundance-unevenness) [2530], an appropriate numerical extrapolation procedure to estimate the number of undetected species and the relative abundances of each of them, was implemented for each of the five incomplete samplings. These numerical extrapolations prove, retrospectively, being mandatory to avoid severe bias in the description and ecological interpretation of the recovery process, as will be shown later in section 4.3.

\subsection{The Numerical Extrapolation Proce- dure and Its Exploitation}

A recently developed extrapolation procedure allows a least-biased estimation of the number of undetected species and can even provide, in addition, estimates of the respective abundances of each of these undetected species, as detailed in section 3.2.1. Thus, once properly numerically completed (and only when it is so [27]), the distribution of species abundances provides synthetic data, in both qualitative and quantitative terms, about the underlying process that drives the hierarchical structuring of species abundances within community [31-35].

\subsubsection{Implementation of the procedure of numerical extrapolation}

* Total species richness: The least-biased estimation of the number of those species that remained unrecorded during partial sampling and the resulting estimation of the total speciesrichness of the partially sampled community are computed according to the procedure defined in references $[5,6]$ and briefly summarized in Appendix 2, based on the numbers $f_{x}$ of species observed $x$-times during partial sampling $(x=1$ to 5$)$. The same procedure allows to derive the least-biased extrapolation of the "Species Accumulation Curve", which predicts the expected increase in the number of newly recorded species, $R(N)$, as a function of the growing sampling size $\mathrm{N}$ (N: number of currently recorded individuals); see Appendix 2 for computation. In practice, this extrapolation allows to forecast the likely additional sampling efforts that would be required to obtain any desirable increment in sampling completeness.

* Species Abundance Distribution: As mentioned above, the Species Abundance Distribution ("S.A.D.") is intended to provide the basic data necessary (i) to describe the pattern of structuration of species abundances within community and (ii) to qualify and quantify the underlying process that drives this structuration. Yet, to accurately exploit its full potential $[7,36]$, the "S.A.D." requires (i) to be corrected for the bias resulting from drawing stochasticity during sampling of finite size and, still more importantly, (ii) to be completed by numerical extrapolation, to the extent that sampling is suspected to be incomplete, as revealed by the subsistence of singletons (species only recorded once during sampling). The appropriate procedure of correction and of numerical extrapolation of the as-recorded partial "S.A.D." is described in details in reference [7], briefly summarized in Appendix 3 and concretely exemplified in details in reference [37]. Classically, the "S.A.D." is graphically presented with the (log-transformed) abundances, $a_{i}$, plotted against the rank ' $i$ ' of species, the latter being ordered by decreasing values of their relative abundances (with, thus, $a_{1}$ and $a_{S t}$ respectively standing for the highest and the lowest abundances in a community of $S_{t}$ species).

\subsubsection{Abundance unevenness: The pattern of species abundance structuration}

Once numerically completed, the "S.A.D." conveys all the relevant quantitative data required to address the internal organization among species within a local community [4]. In turn, the "S.A.D." can be synthetically summarized by two of its major features: the total species richness ' $\mathrm{S}_{\mathrm{t}}$ ' and the degree ' $\mathrm{U}$ ' of unevenness of the abundance distribution. Following [38,39], it is the degree of unevenness - rather than evenness itself - that should be 
preferred to address the hierarchical structuring of species abundances in communities. According to the usual mode of representation of "S.A.D.s", it goes natural to quantify the degree of abundance unevenness $U$ as the average slope of the log-transformed abundance decrease, as already proposed by [40], that is:

$$
U=\left[\log _{10}\left(a_{1}\right)-\log _{10}\left(a_{S t}\right)\right] /\left(S_{t}-1\right)
$$

That is:

$$
U=\left[\log _{10}\left(a_{1} / a_{S t}\right)\right] /\left(S_{t}-1\right)
$$

With $a_{1}$ and $a_{s t}$ standing for the highest and the lowest species abundances in the studied community. Note that choosing this mode of definition of abundance unevenness preserves the symmetric account of abundant species as well as minor species and, thus, the equitable account of each of the co-occurring species, independently of their respective abundances which is admittedly desirable [41]. Thereby contrasting in that, with many commonly used metrics of (un-)evenness which conventionally attribute different weights to co-occurring species, according to their relative commonness or rarity [41].

\subsubsection{The "standardized" species abundance unevenness}

For both descriptive purpose and functional interpretation, it is useful to derive from the "crude" abundance unevenness $U$ (defined above) another, complementary expression of unevenness, the "standardized unevenness index " $\mathrm{I}_{\text {str" }}$ ", defined as the ratio $\mathrm{U} / \mathrm{U}$ ' between the crude unevenness $U$ and the unevenness $U$ ' of a specific abundance distribution taken as a meaningful referential standard [42]. This standard being the well-known "broken-stick" distribution, originally proposed by MACARTHUR in his seminal paper [43]. The selection of the "broken-stick" distribution - as an especially appropriate and meaningful standard in the present context - is justified by two of its main characteristics, briefly argued below and further detailed in Discussion section and reference [42].

The "standardized unevenness index " $\mathrm{I}_{\text {str }}$ " = U/U', is thus defined as:

$$
\begin{aligned}
& \mathrm{I}_{\mathrm{str}}=\left[\log _{10}\left(\mathrm{a}_{1} / \mathrm{a}_{\mathrm{St}}\right) /\left(\mathrm{S}_{\mathrm{t}}-1\right)\right] /\left[\log _{10}\left(\mathrm{a}_{1} / \mathrm{a}_{\mathrm{St}}\right) /\left(\mathrm{S}_{\mathrm{t}}-1\right)\right] \\
& \mathrm{I}_{\mathrm{str}}=\log _{10}\left(\mathrm{a}_{1} / \mathrm{a}_{\mathrm{St}}\right) / \log _{10}\left(\mathrm{a}_{1} / \mathrm{a}_{\mathrm{St}}\right)
\end{aligned}
$$

With $a_{1}$ and $a_{\mathrm{st}}$ standing for the highest and the lowest abundances in the studied community and $a_{1}$ and $a_{\text {St }}$ standing for the highest and the lowest abundances in the corresponding "broken-stick" distribution for the same species richness $S_{t}$. The distribution of abundances for the "broken-stick" model and the corresponding abundance unevenness U' (with U' being a univocal function, $U^{\prime}\left(S_{t}\right)$, of $S_{t}$ ) are computed according to $[31,42,43]$, see also Appendix 4 .

The standardization of the crude unevenness $U$ to the corresponding "broken-stick" unevenness U' answers positively the two following points, which highlight the major interest of considering the "standardized unevenness" index " $\mathrm{I}_{\mathrm{str}}$ ":

- $\quad$ From a descriptive point of view, the crude unevenness $U$ has the major inconvenient of being partly dependent upon speciesrichness [4,31,34,41,44-52]. This makes it inappropriate (a serious source of bias) when comparing communities differing in species richness: indeed, as claimed in reference [41]: "to make sense, (un)evenness must be independent of species richness". Now, being univocally dependent on species-richness [31,42], the "broken-stick" unevenness U' precisely conveys this very part of the crude unevenness $U$ which is (negatively) dependent upon species-richness, as demonstrated in reference [42]. Accordingly, the "standardized" abundance unevenness, $\quad \mathrm{I}_{\text {str }}=\mathrm{U} / \mathrm{U}^{\prime}$, is formally independent of species-richness, as duly required for making reliable comparisons between communities, whatever may be their difference in species-richness;

- As regards, now, the functional point of view, the standardization of the crude abundance unevenness by reference to the broken-stick distribution is also especially appropriate. Indeed, since the broken-stick distribution is functionally associated to the "contiguous, nonoverlapping" niche pattern [43], this means that $I_{\text {str }}=1$ refers to this particular nonoverlapping niche pattern involving no interspecific competition. Conversely, the more $l_{\text {str }}$ is found to exceed unity, the stronger is the intensity of interspecific competition among co-occurring species at niches overlaps (resulting from interspecific contests in the exploitation of shared resource at niche overlaps). 
In short, the "standardized abundanceunevenness" $I_{\text {str }}$ accounts for how much the niche-diversification (i.e. the degree of efficient resource partitioning among co-occurring species) is actually restrained within the considered species community. The account "currency" of this restriction in niche diversification being in term of increased abundance-unevenness, in other words of steeper average slope of the species abundance distribution).

In particular, $I_{\text {str }}($ when $>1)$ takes into account by how much is multiplied the abundanceunevenness (the average slope of the species abundance distribution), as a direct consequence of the intensity of interspecific competition at niche overlaps. That is, while unevenness $U$ is equal to the corresponding "broken-stick" value, $U$ ' when niche display is efficiently diversified (i.e. contiguous non-overlapping niche display), it becomes $U=U^{\prime} . I_{\text {str }}$ as soon as insufficient niche diversification triggers the onset of interspecific competition for shared resource at niche overlaps, according to the level of density in competing individuals.

Conversely, $\left(1 / \mathrm{I}_{\mathrm{str}}\right)$ mirrors to what extent the niches display is efficiently diversified, that is how much resource partitioning among co-occurring species is efficiently improved.

Thus, the standardized unevenness index $\mathrm{I}_{\text {str }}$ features especially relevant at both the descriptive and the interpretative points of view [42].

At last, in addition to $S_{t}, U, I_{s t r}$, a fourth useful descriptor of species structuration within community is the overall range, $R_{a}$, of species abundances which, in terms of conventionally log-transformed abundances, is defined as:

$$
R_{a}=\left[\log _{10}\left(a_{1} / a_{S t}\right)\right]
$$

With $a_{1}$ and $a_{\mathrm{St}}$ standing for the highest and the lowest species-abundances in the studied community. That is, as well, from equations (1) \& (2):

$$
R_{a}=\left(S_{t}-1\right) \cdot U=\left(S_{t}-1\right) \cdot U^{\prime} \cdot I_{s t r}
$$

And for the corresponding "broken-stick" distribution:

$$
R_{a}^{\prime}=\left(S_{t}-1\right) \cdot U^{\prime}
$$

It is important to emphasize that the variations of the overall range of species abundances $R_{a}$ are mainly driven by the variations of the lowest abundance $a_{s t}$, while, on the contrary, $a_{1}$ varies comparatively very little: see empirical evidence in [42] and theoretical argumentation in Appendix 5 . Besides, it is the abundance $\mathrm{a}_{\mathrm{St}}$ of the rarest species which is more decisive as regards the maintenance of species richness, since any further decrease of the lowest abundance $a_{\mathrm{St}}$ likely increases the risk of possible dislodgement and subsequent local extinction of the rarest species. This makes two good reasons to devote particular attention, beyond $\mathrm{R}_{\mathrm{a}}$, to the level of the lowest abundance $a_{S t}$. So that, in this respect, $a_{S t}$ deserves also being considered as an essential descriptor of natural species communities, in addition to $\mathrm{S}_{\mathrm{t}}, \mathrm{U}$ and $\mathrm{I}_{\mathrm{str}}$.

\subsubsection{Statistical testing}

The statistical significance of the regression of the intensity of interspecific competition (mirrored by $I_{\text {str }}$ ) against species-richness and the overall density of individuals (implemented $\S 5.2$ ) is estimated according to the conventional Student t-test procedure.

\section{RESULTS}

\subsection{Estimated Total Species Richness of the Gastropod Community before Its Destruction and Along Its Progressive Recovery}

As mentioned above, due to the subsistence of one or several singletons (species recorded only once during sampling), the samples reported for years 1972, 1974, 1977, 1987 and 1997 were considered incomplete and therefore submitted to 'least-biased' numerical extrapolations (previous examples of application of this procedure are provided in references [37,53-62]). Table 1 provides, at each date, the reported sampling data and the corresponding extrapolated numbers of those species that had remained undetected, from which is immediately derived the estimated total species richness.

\subsection{Species Abundance Distributions Numerically Completed}

The bias-corrected and numerically-extrapolated Species Abundance Distributions (S.A.D.s) are provided in Figs. 1 to 6.

The corresponding "broken-stick" distributions (i.e. computed for the same species richness) are also plotted on the same Figures, for the 
purpose of direct comparisons to this referential standard. The crude species abundance unevenness $U$ is either equal (in 1968), slightly larger (in 1972, 1987, 1997) or substantially larger (in 1974, 1977) than is the crude unevenness $U^{\prime}\left(S_{t}\right)$ in the corresponding "brokenstick" distributions, computed for the same species-richness $S_{t}$. The differences are more precisely quantified in term of the standardized unevenness index $I_{\text {str }}\left(=U / U^{\prime}\left(S_{t}\right)\right)$, as shown in Table 2, which also provides complementary information relative to species abundances.

\subsection{Evolution of the Main Characteristics of the Distribution of species Abundances within Community along Thirty Years of Recovery Process}

Due to their particular socio-ecological significance, four characteristics of the Species Abundance Distribution were especially followed during the course of recovery of the gastropod community after its complete destruction: the species richness $\mathrm{S}_{\mathrm{t}}$, the crude abundance unevenness $\mathrm{U}$, the standardized abundance unevenness $\mathrm{I}_{\mathrm{str}}$ and the relative abundance $\mathrm{a}_{\mathrm{St}}$ of the rarest species. The respective variations of these four parameters from 1968 (before destruction) up to 1997 , when recovery seems having approach a new "equilibrium", are provided in Figs. 7 to 10 . These Figures also provide, for instructive comparison, the results that would have been derived if only nonextrapolated field data would have been considered. As is immediately evident, and although the degrees of sampling incompleteness were not excessive (all completeness levels $>75 \%$ ), yet strikingly different, strongly biased results - and consequently irrelevant associated ecological interpretations - would have resulted from ignoring sampling incompleteness and neglecting the required numerical extrapolations of incomplete samplings. Of course, bias are all the more stronger than sampling completeness is lower, with bias being thus particularly severe for years 1974 and 1977 (completeness levels 80\% and $76 \%$ only).

Complementary to these four descriptors of Species Abundance Distributions, the variations of the overall density D of individuals (all cooccurring species considered together) deserves consideration: Fig. 11. And this not only for descriptive purpose but also, as will be seen later, for the relevant interpretation of the variations in interspecific competition intensity, because the density of individuals is part of the factors triggering interspecific contests at niches overlaps.

The socio-ecological interpretations that can be derived from the respective variations of all these major factors, contributing together to the species organization within community, are further analyzed in the Discussion section.

\subsection{Rough Classification of Species, According to their Respective Answer during the Recovery Process of the Gastropod Community at Fangataufa}

The overall 24 gastropod species identified on reef flat and edge at Terme-Sud of Fangataufa atoll, before and after nuclear tests, can be roughly distributed in four main types, according to their recovery status:

* A - species originally present and with consistent recovery answer:

Turbo setosus Gmelin 1791, Tenguella granulata (Duclos 1832), Morula uva Röding 1798, Drupa ricinus Linnaeus 1758, Mitra litterata Lamarck 1811, Conus ebraeus Linnaeus 1758, Conus miliaris Hwass in Bruguière 1792 , Conus nanus Sowerby I 1833, Conus sponsalis Hwass in Bruguière 1792.

\footnotetext{
* B - species originally present and with irregular recovery answer:
}

Patella flexuosa Quoy \& Gaimard 1834.

* C - species originally absent but with seemingly well-established recovery answer:

Nerita plicata Linnaeus 1758, Monetaria moneta Linntaeus 1758, Imbricaria conovula Quoy \& Gaimard 1834.

* D - species originally absent with transient or tardive recovery answer:

Turbo argyrostomus Linnaeus 1758, Cerithium echinatum Lamarck 1822, Cerithium nesioticum Pilsbry \& Vanatta 1906, Cerithium sp., Tectarius grandinatus Gmelin 1791, Canarium maculatum Sowerby II 1842, Drupa grossularia Röding 1798, Drupa morum Röding 1798, Mancinella armigera Link 1807, Conus chaldeus Röding 1798, Conus rattus Hwass in Bruguière 1792. 
Béguinot; ARRB, 36(1): 77-110, 2021; Article no.ARRB.66275
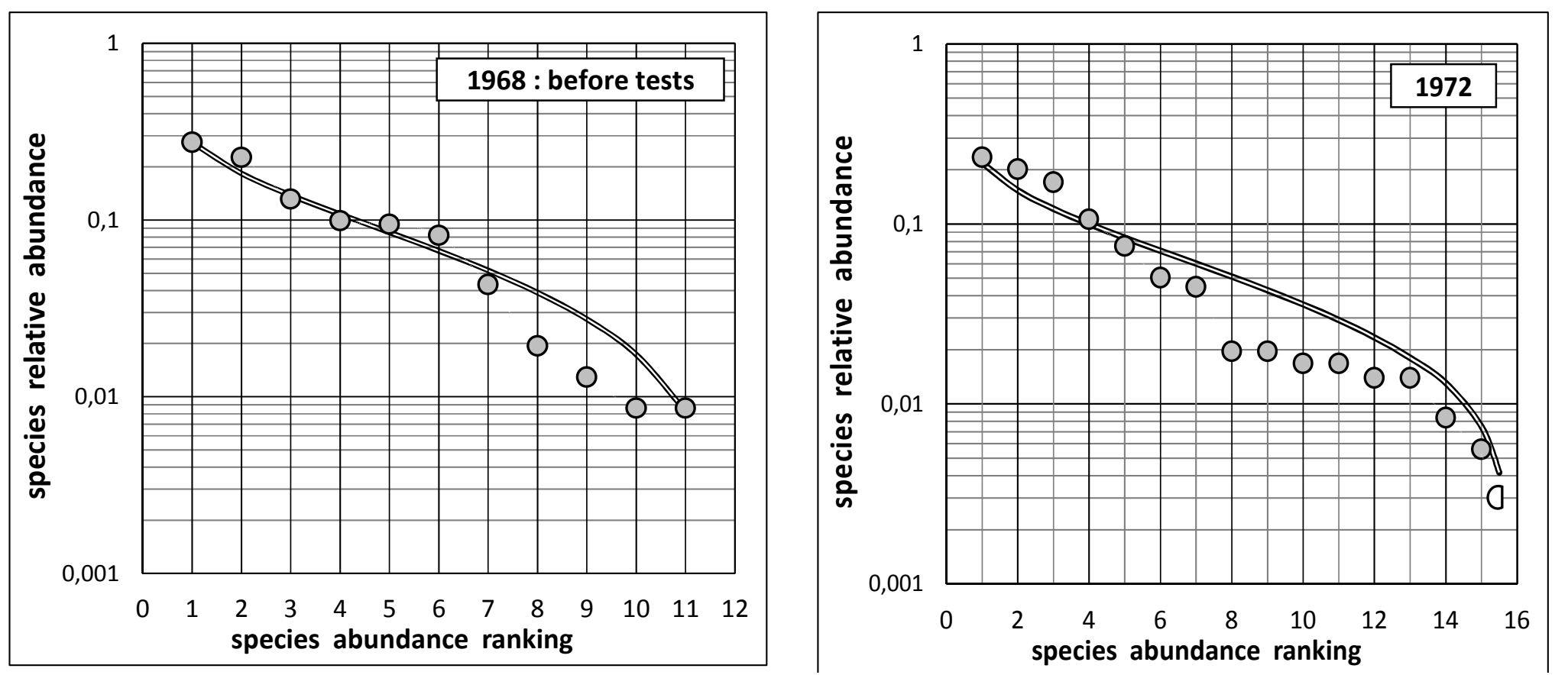
Béguinot; ARRB, 36(1): 77-110, 2021; Article no.ARRB.66275
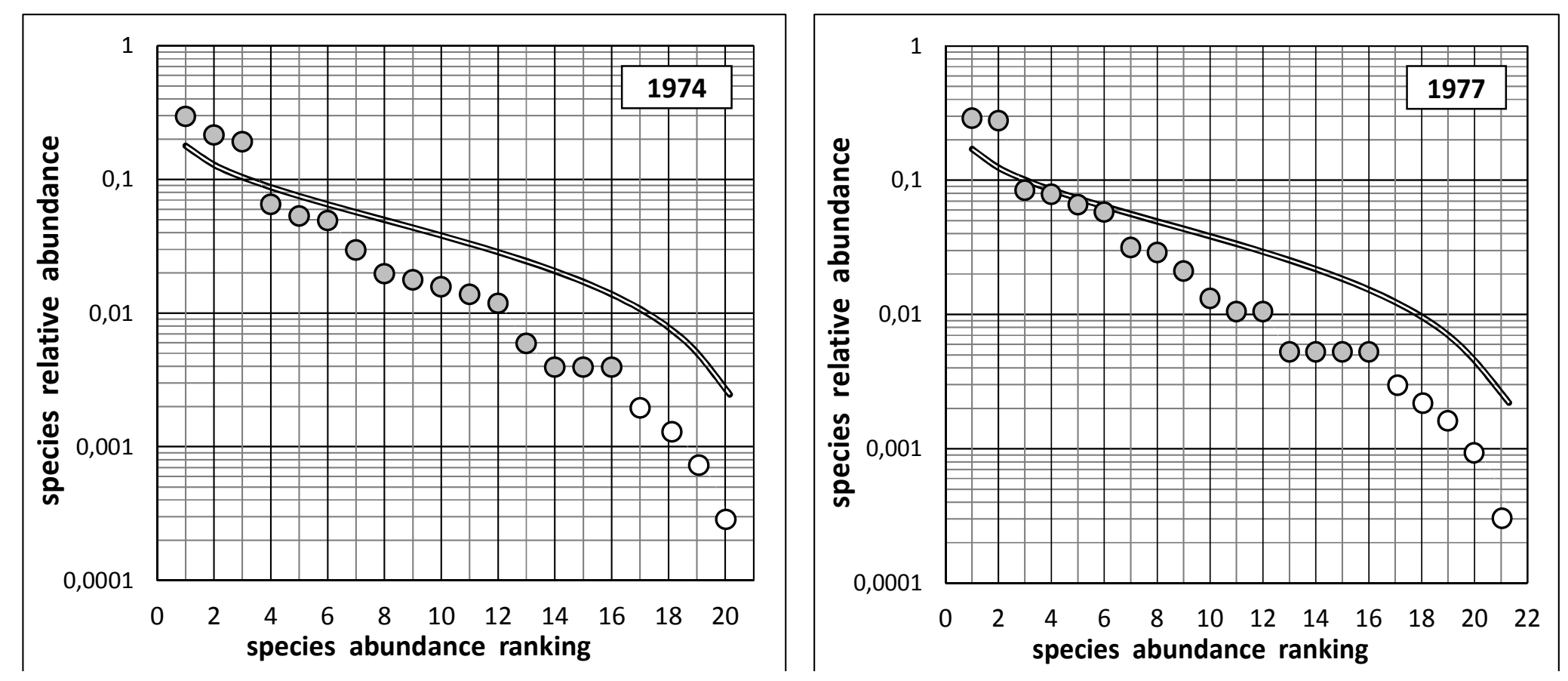

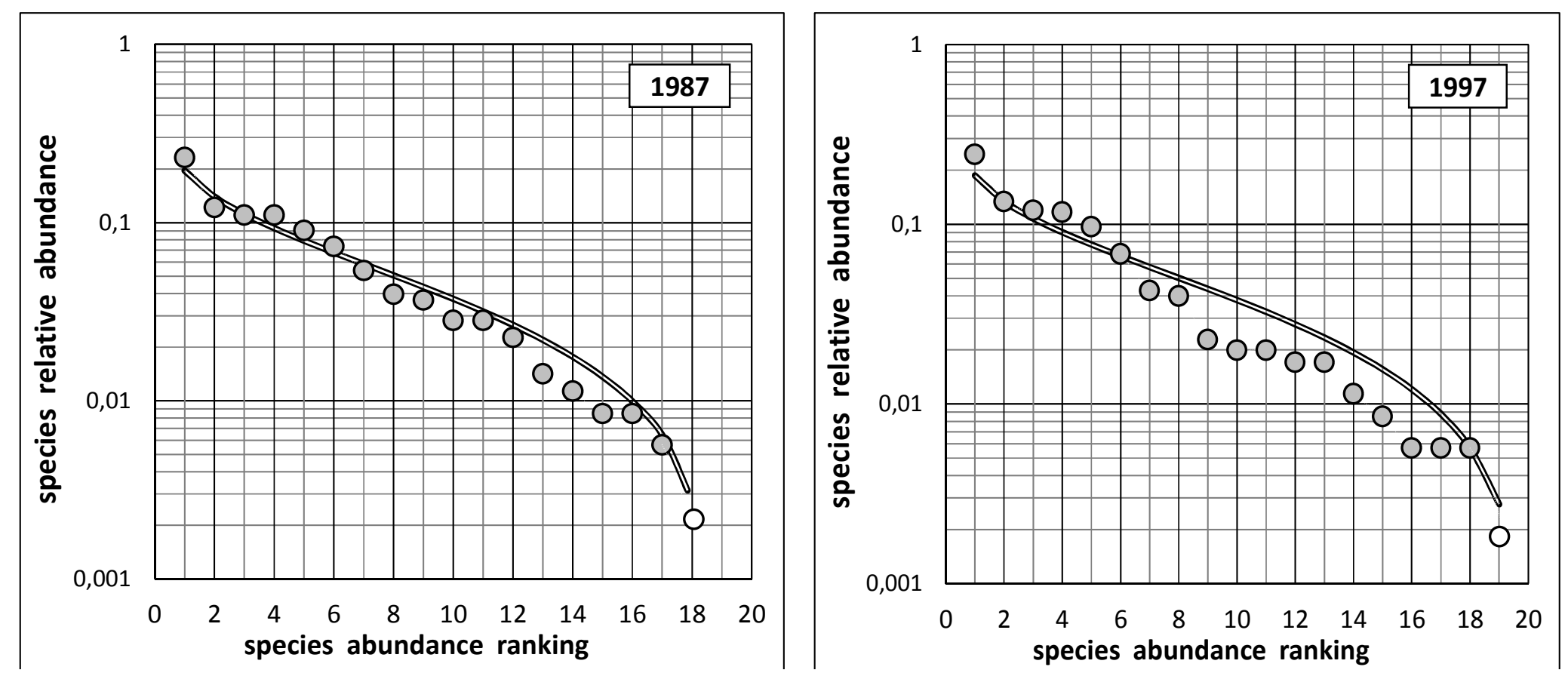

Figs. 1 to 6 . The corrected and completed species abundance distributions of the studied reef-associated gastropod community before (1968) and after nuclear blasts, i.e. from 1972 to 1997. As recorded data: grey discs; numerically extrapolated part of the abundance distribution: white discs.

For comparison, the abundance distribution of the corresponding "broken-stick" model, computed at the same species richness, is plotted as a double line. 


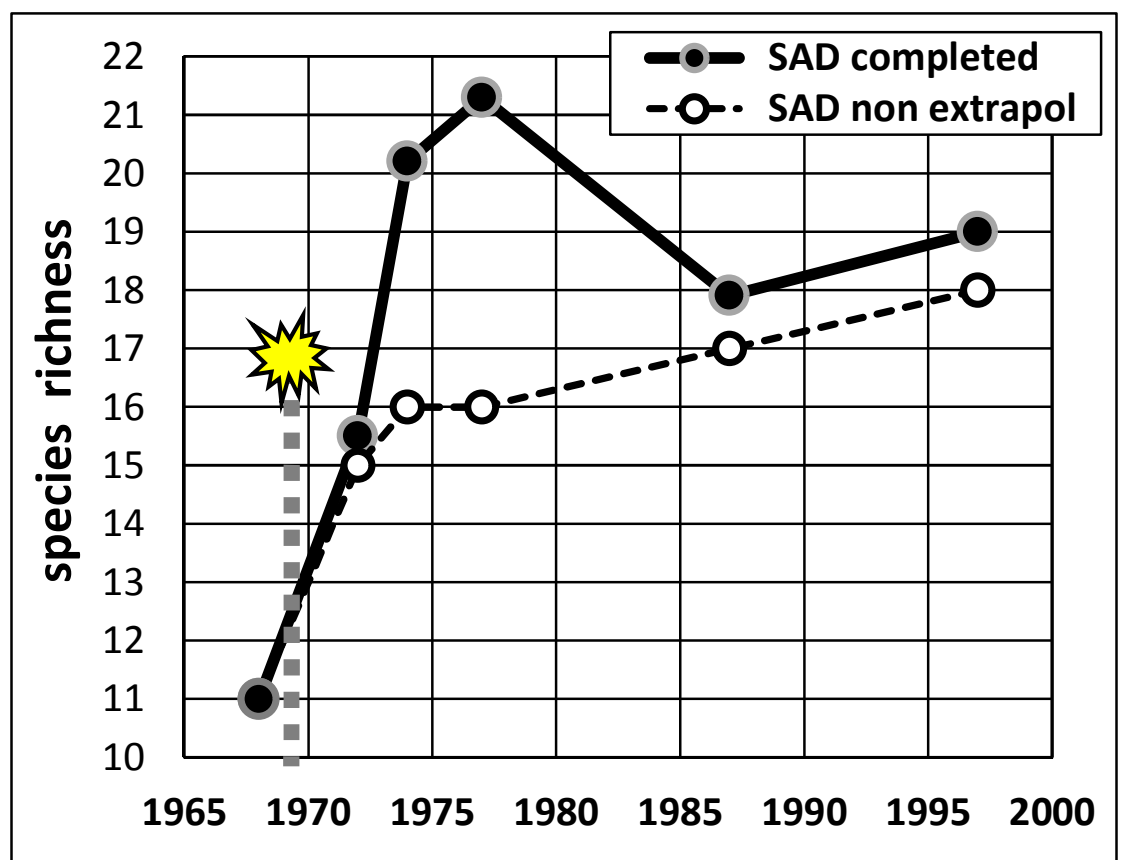

Fig. 7. Variations of total species richness $S_{t}$ along the recovery process

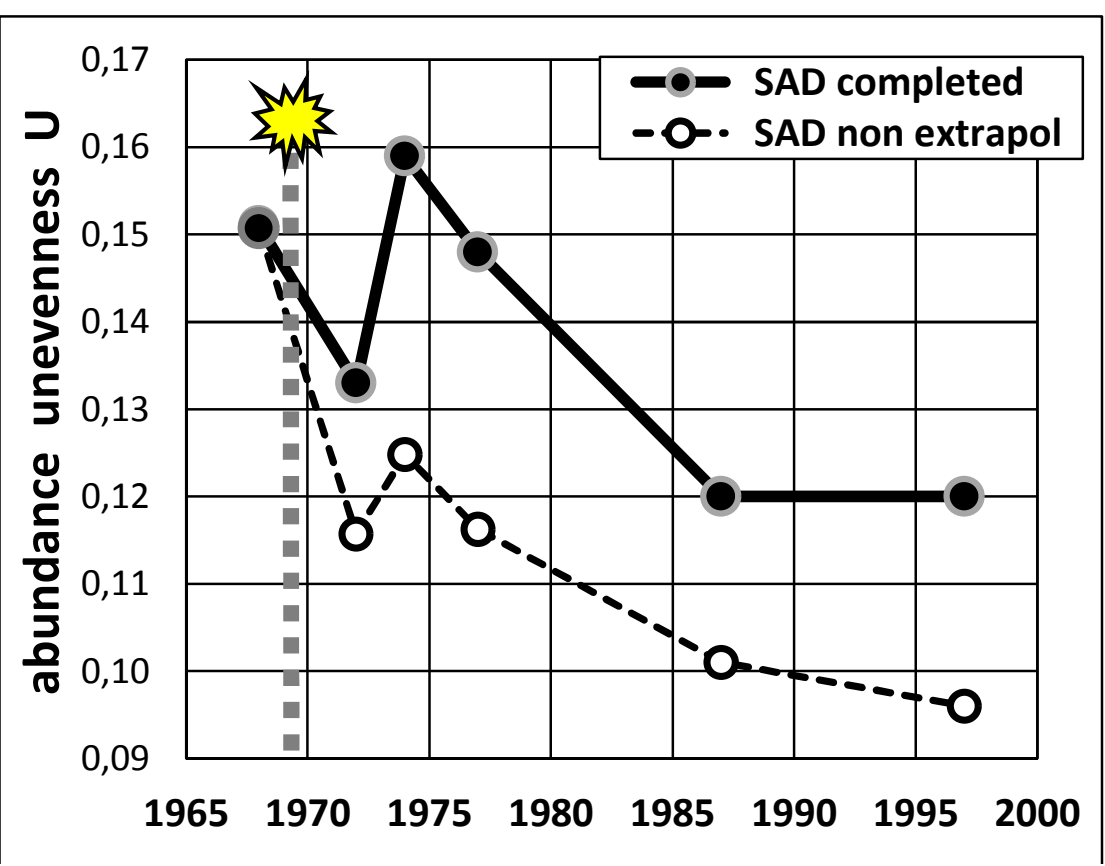

Fig. 8. Variations of crude abundance unevenness $U$ along the recovery process 


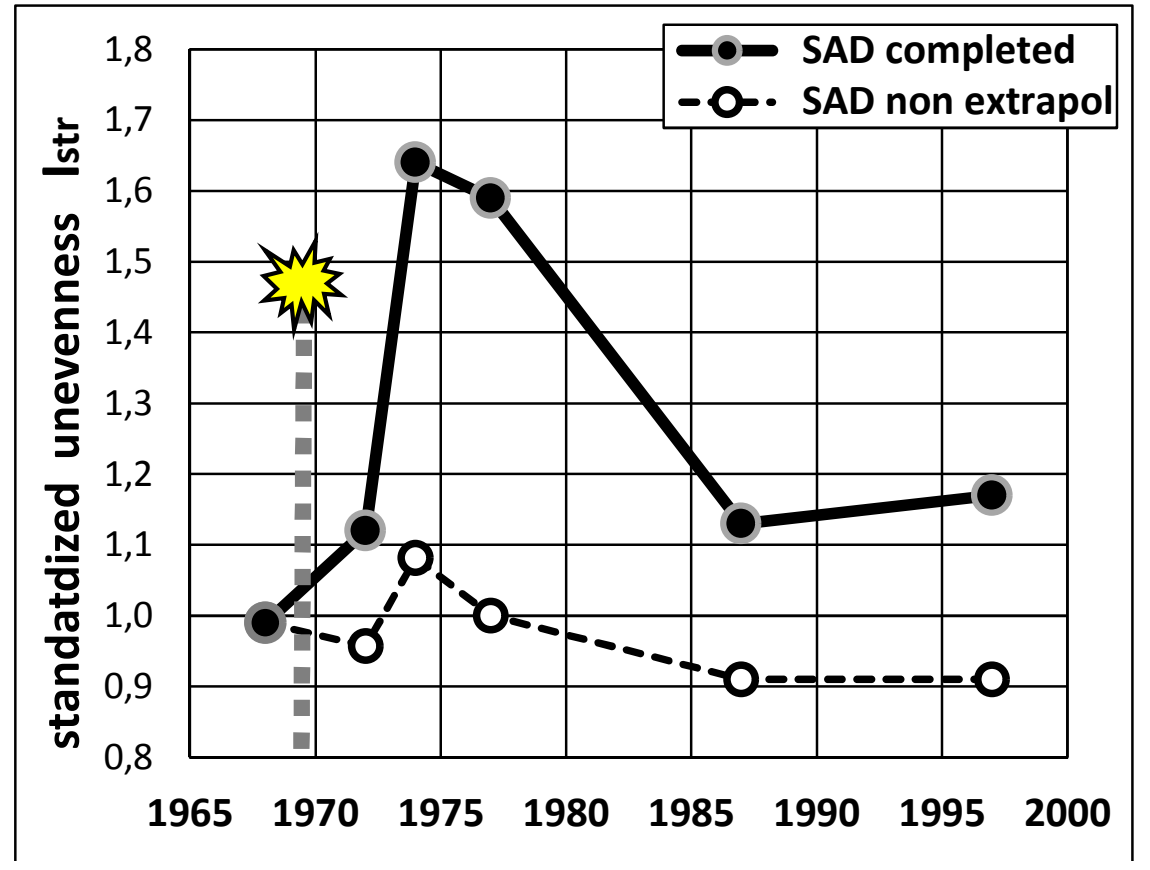

Fig. 9. Variations of the standardized unevenness $I_{\text {str }}$ along the recovery process

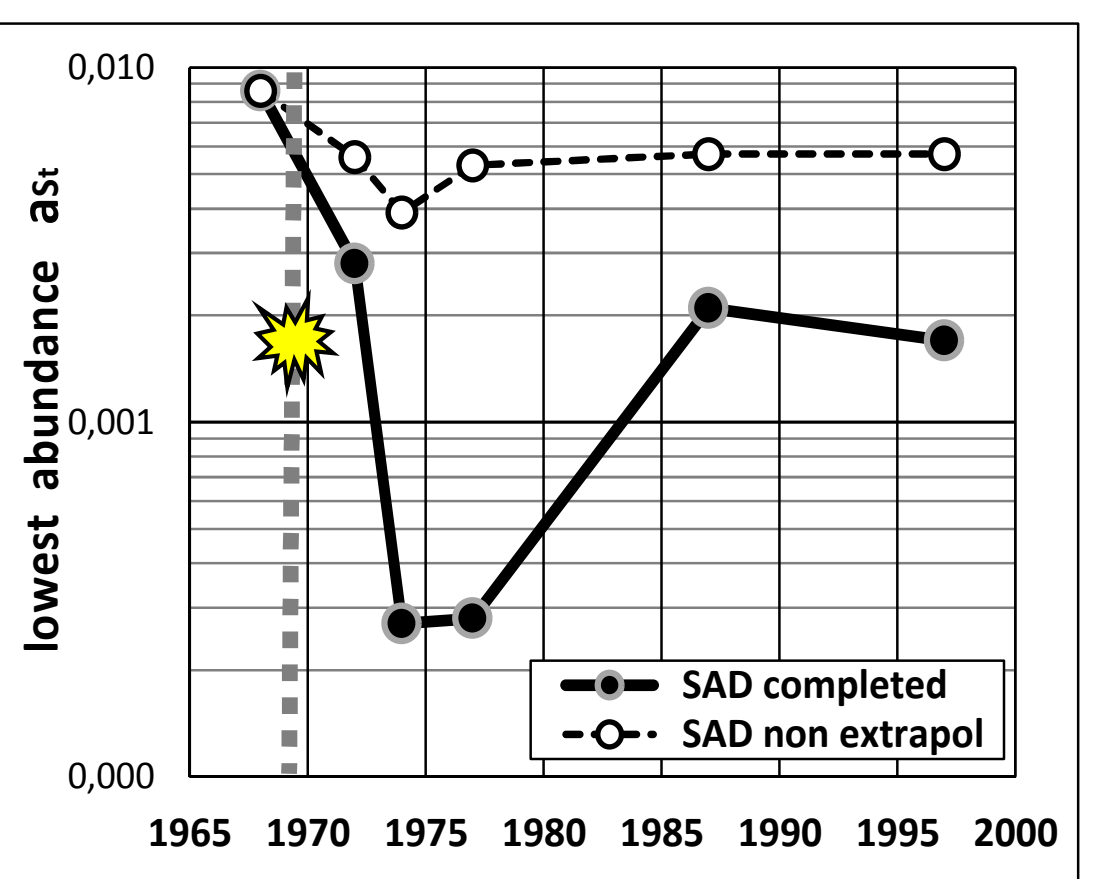

Fig. 10. Variations of lowest species abundance $a_{\mathrm{st}}$ along the recovery process 
Table 1. The number of collected individuals $N_{0}$, the number of recorded species $R_{0}$, the type of nonparametric estimator (Jackknife series) selected as being the least-biased one, the estimated number $\Delta$ of unrecorded species, the resulting estimate of the "true" total species richness $S_{t}\left(=R_{0}+\Delta\right)$, the resulting estimated level of sampling completeness $R_{0} / S_{t}$

\begin{tabular}{lllllll}
\hline Conus community & $\mathbf{1 9 6 8}$ & $\mathbf{1 9 7 2}$ & $\mathbf{1 9 7 4}$ & $\mathbf{1 9 7 7}$ & $\mathbf{1 9 8 7}$ & $\mathbf{1 9 9 7}$ \\
\hline Number of collected individuals $\mathrm{N}_{0}$ & 454 & 342 & 489 & 361 & 335 & 332 \\
Number of recorded species $\mathrm{R}\left(\mathrm{N}_{0}\right)$ & 11 & 15 & 16 & 16 & 17 & 18 \\
Selected least-biased estimator & $/$ & $\mathrm{JK}-1$ & $\mathrm{JK}-5$ & $\mathrm{JK}-5$ & $\mathrm{JK}-1$ & $\mathrm{JK}-2$ \\
Number of unrecorded species $\Delta$ & 0 & 0.5 & 4 & 5 & 1 & 1 \\
\hline Total species richness $\mathrm{S}_{\mathrm{t}}$ & $\mathbf{1 1}$ & $\mathbf{1 5 . 5}$ & $\mathbf{2 0}$ & $\mathbf{2 1}$ & $\mathbf{1 8}$ & $\mathbf{1 9}$ \\
\hline sample completeness $\mathrm{R}_{0} / \mathrm{S}_{\mathrm{t}}$ & $100 \%$ & $\mathbf{9 7 \%}$ & $80 \%$ & $76 \%$ & $94 \%$ & $95 \%$ \\
\hline
\end{tabular}

Table 2. A synthetic summary of the main quantitative features of the hierarchical organization of species abundances within community: (i) the total species richness $S_{t}$ of the community ; (ii) the relative abundances $a_{1}$ and $a_{s t}$ of the most and the least abundant species (i.e. species of ranks 1 and $S_{t}$ ) ; (iii) the same, $a^{\prime}{ }_{1}$ and $a$ 'st, for the "broken-stick" distribution, (iv) the crude abundance unevenness $U=\log \left(a_{1} / a_{\mathrm{St}}\right) /\left(\mathrm{S}_{\mathrm{t}}-1\right)$; $(\mathrm{v})$ the abundance unevenness in the corresponding "broken-stick" distribution: $U$ ' $=\log \left(a^{\prime}{ }_{1} / a^{\prime}{ }_{S t}\right) /\left(S_{t}-1\right)$; (vi) the "standardized" unevenness index $I_{s t r}=U / U$ '; (vii) the overall range of species abundances $R_{a}$

\begin{tabular}{lllllllllll}
\hline & $\mathbf{S}_{\mathbf{t}}$ & $\mathbf{a}_{\mathbf{1}}$ & $\mathbf{a}_{\mathbf{S t}}$ & $\mathbf{a}_{\mathbf{1}} / \mathbf{a}_{\mathbf{S t}}$ & $\mathbf{a}_{1}{ }_{1}$ & $\mathbf{a}_{\mathbf{S t}}$ & $\mathbf{U}$ & $\mathbf{U}^{\prime}\left(\mathrm{S}_{\mathbf{t}}\right)$ & $\mathbf{I}_{\text {str }}$ & $\mathbf{R}_{\mathbf{a}}$ \\
\hline $\mathbf{1 9 6 8}$ & 11 & .275 & .0086 & 32 & .275 & .0083 & .151 & .153 & 0.99 & 1.51 \\
$\mathbf{1 9 7 2}$ & 15.5 & .235 & .00279 & 84 & .218 & .0042 & .133 & .119 & 1.12 & 1.93 \\
$\mathbf{1 9 7 4}$ & 20 & .295 & .00027 & 1092 & .178 & .0025 & .159 & .097 & 1.64 & 3.04 \\
$\mathbf{1 9 7 7}$ & 21 & .289 & .00028 & 1032 & .171 & .0022 & .148 & .093 & 1.59 & 3.01 \\
$\mathbf{1 9 8 7}$ & 18 & .232 & .00218 & 106 & .196 & .0031 & .120 & .106 & 1.13 & 2.03 \\
$\mathbf{1 9 9 7}$ & 19 & .244 & .00174 & 140 & .187 & .0028 & .119 & .102 & 1.17 & 2.15 \\
\hline
\end{tabular}

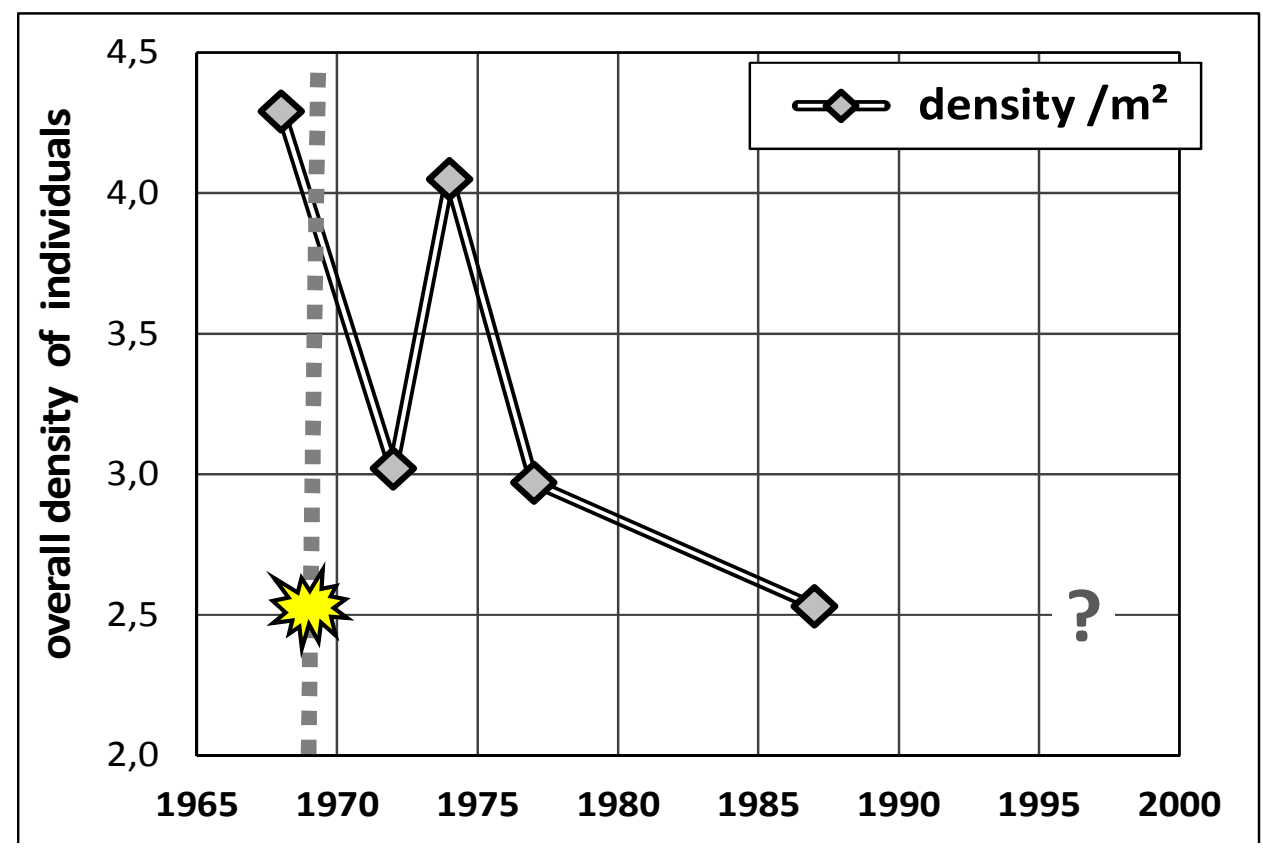

Fig. 11. The overall density $D$ of individuals per unit area (number of individuals per $\mathrm{m}^{2}$ - all species being taken together) before and along the recovery process. No reported data was made available for year 1997 
Half of these species, belonging to one or the other among the four types above, are illustrated below.

The twelve species attributed to types " $A$ " and "C" obviously endure positively the strongly competitive transient phase, during $1974-1977$ (see Discussion, section 5.1) although, the three species attributed to type "C" had failed to subsist in the period preceding nuclear tests.

The twelve other species, attributed to types "B" and " $\mathrm{D}$ ", seem encountering more or less strong difficulty to (re-) establish, probably due to the harsh interspecific competition, either at the transient strongest competitive phase (1974 1977) or even later, when competition reduced but still remained somewhat higher than before nuclear tests (see Discussion, section 5.1).

\section{DISCUSSION}

Nuclear experiments performed on Pacific atolls during the second half of the last century had offered exceptional opportunities to monitor the recovery of completely destroyed marine communities, and this at a far larger scale than what could be practically implemented in the context of purely biological studies $[4,5,63,64]$. And, indeed, the effect of scale on recovery process is admittedly recognized as being of major importance [63].

The four main descriptors of the hierarchical organization of species within the monitored marine gastropod community - namely: speciesrichness, crude and standardized abundance unevenness and the lowest level of species abundance - all show remarkably strong variations along the progressive recovery of the monitored community. Analyzing these variations, both separately and conjointly, does reveal highly instructive, as regards both:

- practical concern: to which degree this marine community proves being resilient after its complete destruction and,

- speculative considerations, especially in favor of a better understanding of how proceeds (i) the accommodation of an increasing number of recruited species, (ii) the associated (transient) increase of competitive interactions and, finally, (iii) the resulting hierarchic organization of species-abundances, all along the recovery progress. And how the strongly competitive, highly unstable transient stage of recovery finally gives up, opening the way to a less unstable situation.

\subsection{Ecological Interpretations of the Variations of Species Richness, Abundance Unevenness and Lowest Abundance along the Community Recovery}

*Species richness $S_{t}$ : as compared to the predestructing situation (1968), species richness, at first, strongly increases from zero, even rapidly generating a pronounced humpback at years 1974 and 1977, before, finally, tending to stabilization: Fig. 7. The transient, excessively high species richness - up to twice the original level - seems typical of a first stage of colonization (here, re-colonization). Indeed, at the beginning of this first stage, the speciesrichness is only constrained by abiotic filtering. It is later only that a second filtering process will contribute to dislodge the less competitive species, as a result of the transient severe interspecific-competition triggered by the excessive number of recruited species. So that, finally, the species-richness will strongly decrease - while yet remaining at a moderately higher level than before community destruction and this for an unknown period. Interestingly, a similar, relatively long-standing improvement in species richness after the recovery following destruction by nuclear experiments was also reported for coral assemblages [64].

${ }^{*}$ Crude abundance unevenness $U$ : opposite to species richness, the crude unevenness shows a decreasing trend, as expected from its partially negative dependence upon species richness (see section 3.2.3, Appendix 1 and reference [42]). A decrease, yet, interrupted transitorily by a marked humpback at years 1974 and 1977 (Fig. 8), answering a sharp increase in interspecific competition intensity, as further analyzed below.

*Standardized abundance unevenness $l_{\text {str }}$ : starting from $\mathrm{I}_{\mathrm{str}} \approx 1$ before destruction (i.e. no significant functional overlaps among speciesassociated niches resulting in negligible interspecific competition), the standardized unevenness eventually return to almost the same low level $\left(I_{\text {str }} \approx 1.1-1.2\right)$, but after a very pronounced humpback $\left(I_{\mathrm{str}} \approx 1.59-1.64\right)$, still more prominent than the one observed for species richness at the same period: Fig. 9. In compliance with the functional interpretation attached to standardized unevenness (see section 3.2.3, Appendix 1 and reference [42]), 


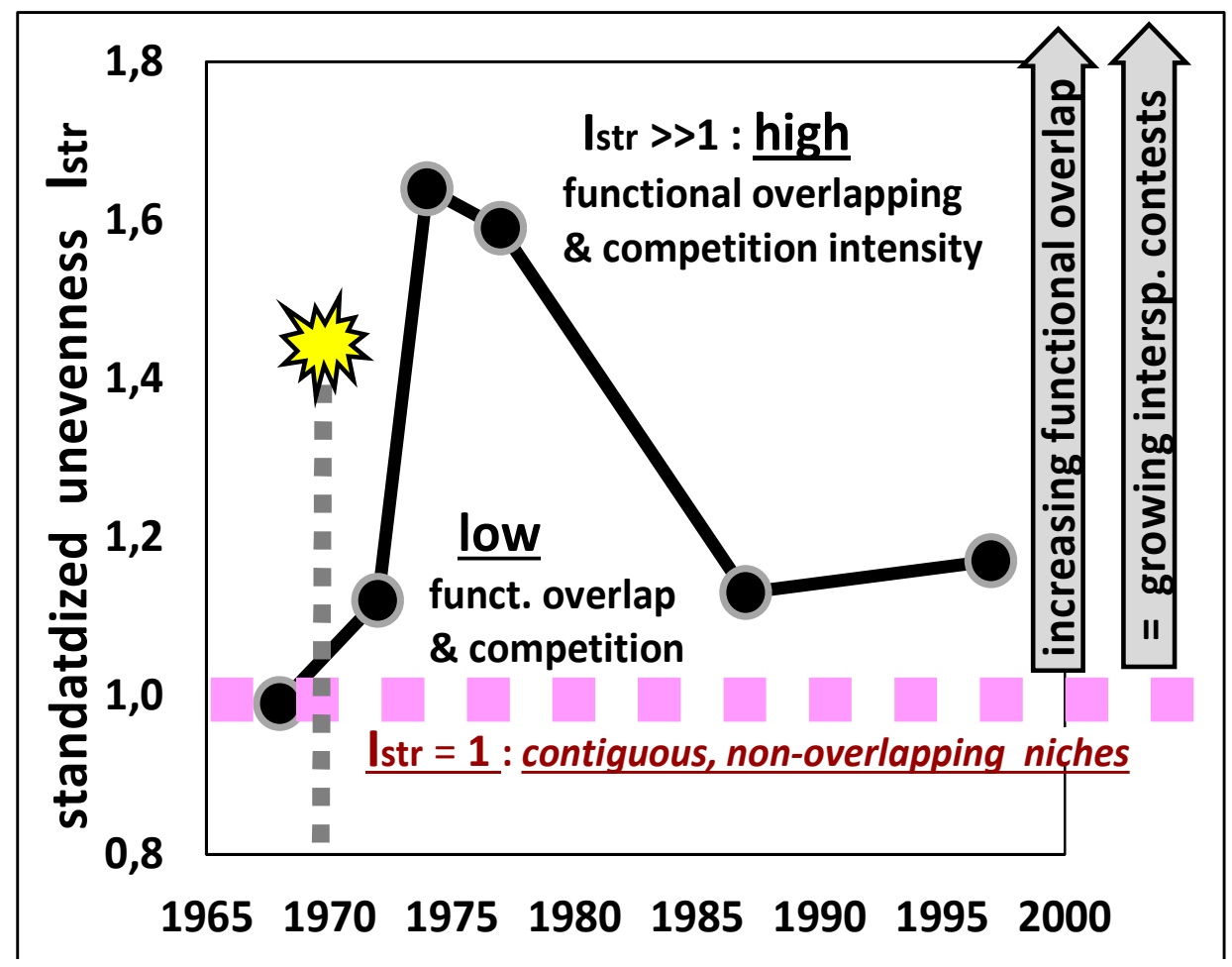

Fig. 12. Ecological interpretation of the variations in the intensity of interspecific competition (mirrored by the standardized abundance unevenness $I_{\text {str }}$ when $>1$ ), driven by the severity of interspecific contests for shared resource at functional overlaps among partially intersecting niches. The degree of "functional overlap" depending on both (i) the extent of geometrical overlapping (promoted by increasing species richness and the corresponding, overcrowding number of associated niches) and (ii) the density of individuals sharing the same kind of resource at these niche overlaps

this mirrors the brutal onset of an intense interspecific-competition, expected to originate from severe interspecific contests for shared resource at niche overlaps during the period 1974 - 1977, due to the obviously excessive number of newly recruited species, following complete destruction (Fig. 12).

In turn, this severe competition for shared resource likely finds its origin in the concomitant combination of (i) the development of substantial niche overlaps between more numerous niches associated to an ever-increasing number of newly recruited species (Fig. 7) and (ii) a clear pic in the overall density of individuals at the same time (Fig. 11) which likely triggers harsher interspecific contests at those niche overlaps - which therefore become "strongly functional" overlaps. Additional quantitative support to this qualitative argumentation is provided in following section 5.2 .
* Lowest species abundance $a_{S t}$ : the variations in the relative abundance of the rarest species show an almost perfect mirror symetry to the trend standing for the standardized unvenness $I_{\text {str }}$ described above. This is no surprise since, as already mentioned, the variations of the overall range of species abundance $R_{a}$ (that is variations in unevenness at a same given species richness, highlighted by $\mathrm{I}_{\mathrm{str}}$ ) are mainly accommodated by $a_{\text {St }}$ (rather than $a_{1}$ ): see Appendix 5. From an ecological point of view, the deep trough in the relative abundance of the rarest species, during the period 1974 - 1977, had likely put the subsistence of these rarest species at greater risk, due to their stronger exposure to local dislodgement, arguably resulting from either weaker positioning in the interspecific competitive challenge and/or sensitivity to 'Allee' effects. And, indeed, this likely contribute to explain the clear decrease in species richness following year 1977, that is, from 1987 onwards: Fig. 7. 


\subsection{Disentangling the Respective Contributions to Interspecific Competition of Both the Degree of Niche-Overlap and the Density of Individuals}

As already emphasized, the interspecific competition, mirrored by the level of standardized unevenness $I_{\text {str }}$, is expected to increase with both: (i) the degree of geometrical niche-overlap, arguably expected to grow monotonically with the number $S_{t}$ of co-occurring species and (ii) the average density of individuals at these nicheoverlaps, itself mirrored by the overall density $D$ of individuals per unit of area $\left(\mathrm{m}^{2}\right)$.

Based on the observed values of $I_{s t r}, S_{t}$ and $D, a$ linear regression of $I_{\text {str }}$ against $S_{t}$ and $D$ yields:

$$
I_{s t r}=0.0794 S_{t}+0.1987 D-0.740
$$

This linear regression not only fairly well complies with qualitative expectations regarding the respective, positive, roles of species richness and individuals' density in promoting interspecific competition within community. It further exhibits a fairly good quantitative fit with the observed data: Fig. 13. This provides additional empirical support - in now precise quantitative terms - to the rationally expected positive answer of standardized unevenness $I_{\text {str }}$ (accounting for the intensity of interspecific competition) upon both:

* the true species richness $S_{t}$, as far as species richness is arguably expected to enhance the degree of geometrical overlap among increasingly numerous associated niches: $t$-test, $\mathrm{df}=2, \mathrm{t}=10.0, \mathrm{p}=0.01$ and

* the overall density $D$ of individuals per area unit $\left(\mathrm{m}^{2}\right)$, expected to mirror the density of individuals at niche overlaps, triggering stronger interspecific contests therein: $t$-test, $\mathrm{df}=2, \mathrm{t}=4.6, \mathrm{p}=0.04$.

In other words, this result provides complementary convincing support in favor of the niche-pattern appraisal of species organization within communities (as opposed, for example, to the readily and purely stochastic view advocated in the so-called "Neutral Theory", at least when the latter theory is considered stricto-sensu). But - still more precisely - the result above clearly complies fairly well with the conception developed by MACARTHUR, in his seminal paper on the subject [43] (as briefly summarized in section 2 and Appendix 1).

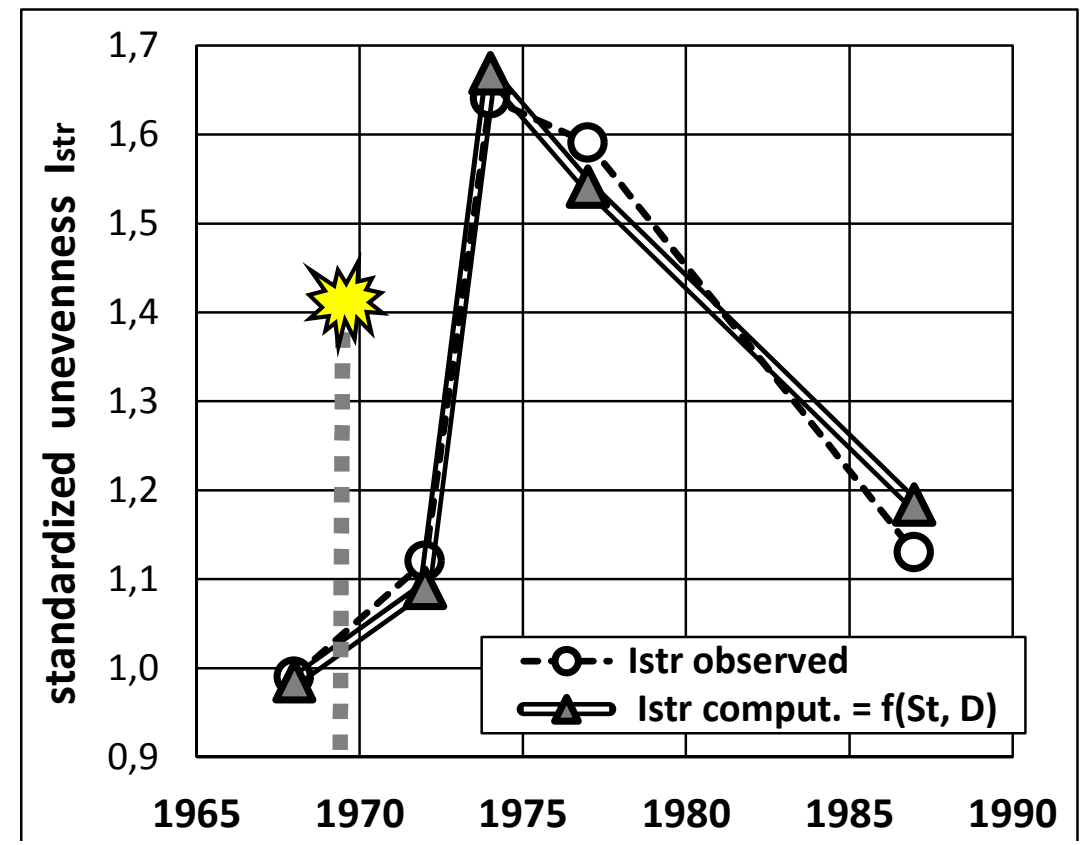

Fig. 13. Comparison between observed and computed (according to equation (6)) variations of the intensity of interspecific competition (reflected here by the variations of the resulting standardized abundance unevenness $I_{s t r}$ ) as a function of its assumed main drivers: (i) the species richness $S_{t}$, promoting niche geometrical overlapping and (ii) the density of individuals $D$, triggering harsher interspecific contest for shared resource at niche overlaps. 


\subsection{Resulting Interpretative Overview of the Recovery Process of the Marine Gastropod Community at Fangataufa Atoll}

The recovery process following complete destruction had involved a re-colonization of the site (recruitment of a new set of species from the neighboring regional pool) which turned out to aggregate significantly more numerous species than before destruction. With, as a result, an expected increase in the degree of nicheoverlaps, triggering in turn, harsh interspecific contests for shared resource at niches overlaps and, consequently, intense interspecific competition, mirrored by the sharp increase of the standardized abundance unevenness $I_{\text {str }}$, reaching values largely in excess of unity.

In 1972, the species richness had already significantly exceeded its original level (Fig. 7), but the intensity of competition (as mirrored by $\mathrm{I}_{\text {str }}$ ) had not much increased yet (Fig. 9). This is because the recovery of individuals' density remained still weak by 1972, well below its original value (Fig. 11) and, therefore, still does not generate significant contest for shared resource at, yet, already important niche geometrical overlaps.

However, two years later, in 1974, the density of individuals had now markedly increased, almost reaching its original value (Fig. 11), so that a high level of interspecific contest for shared resource is now expected to occur within niche overlaps, thereby causing a sharp increase in interspecific competition, as suggested by $\mathrm{I}_{\text {str }}$ now strongly exceeding unity: $I_{\text {str }}$ reaching 1.64 by 1974 (Fig. 9).

Three years later, in 1977, species richness had still slightly increased (Fig. 7), as is likely the case for the associated degree of niche-overlap. But individuals' density had markedly fallen down, presumably due to the onset of the severe interspecific competition as soon as 1974 (Fig. 11). Accordingly, the intensity of interspecific competition had begun to (still very slightly) decrease, yet remaining at a still high level $\left(\mathrm{l}_{\mathrm{str}}=\right.$ 1.59 by 1977: Fig. 9).

This rather strong interspecific competition intensity, during the period 1974 - 1977, should subsequently lead both (i) to a further decrease in the density of individuals and, thereby also (ii) to an increasing exposure of the rarest species to progressively higher risks of disappearance. So that the resulting expected decrease of species richness $S_{t}$, and the additional decrease of individuals' density $D$, now both contribute to the strong decrease of competition intensity. A decrease indeed highlighted by the standardized unevenness $\mathrm{I}_{\text {str }}$ falling down spectacularly from 1.59 to 1.13 , ten years later, in 1987 (Fig. 9). So that, by 1987,17 years after the last nuclear testing, the interspecific competition at niche overlaps had seriously weakened, almost returning back to the original situation, before nuclear experiments. But with species richness (partly inherited from the active recruitment at the first stage of recolonization) still remaining substantially higher than it was originally, in 1968 (Fig. 7).

Thus, although competition intensity had finally cancelled down (almost recovering its original sub-null value, after having reach transient very high levels during the first ten years following the full destruction of the community), the new situation, from 1987 onwards, still markedly differs from the original one. Part of the numerous newly recruited species had finally escaped the elimination by the harsh, transient interspecific competition during the 1974-1977 period and thus could subsequently subsist in the following period, thanks to the vanishing of competitive contest mainly due to still decreasing level of overall density of individuals, which remains now substantially weaker than it was before the destruction of the community (Fig. 11).

A new kind of pseudo-equilibrium, from 1987 onwards, thus seems to replace the original one, established before nuclear tests. While both (pseudo-) equilibria (before tests and after 1987) are likely maintained by a reduced (if not nil) level of interspecific competition $\left(I_{\text {str }} \approx 1\right)$, these two kinds of equilibria significantly differ from each other as regards the way this reduced competitive intensity is obtained. Prior to destruction, it is the relatively low species richness which likely prevents niches intersections and geometrical overlaps, thereby avoiding any source of contest among cooccurring species, in spite of a relatively high density of individuals. On the contrary, after the transient period of recovery 1974-1977, it is now the relatively low density of individuals which reduces, if not avoids, interspecific contest among co-occurring species, in spite of possibly subsisting niches overlaps due to species richness remaining significantly higher than originally. These potentially subsisting geometrical-overlaps thus becoming "non- 
functional", due to the now low density of individuals.

However, it may seem that rendering niche overlaps 'non-functional' in this way (by reducing the density of individuals rather than by suppressing niche overlaps themselves, as originally, before destruction of the community), could lead to a less stable situation than the one prevailing before nuclear tests. Indeed, comparing species lists between 1987 and 1997 shows an important turn-over in species composition during this time interval, with most of rarest species in 1987 (viz Strombus maculatus, Imbricaria conovula and Cypraea moneta) having still more or less further decline, or even disappear by 1997 , likely due to their very low absolute densities. While another species, Patella flexuosa, still rare in 1987, had yet strongly increased in 1997, possibly being in process of restoring its dominant, likely more stable, original position in 1968.

\section{CONCLUSION}

The reported accounts, by LANCTÔT, LEGENDRE \& SALVAT $[4,5]$ of the recovery of a reef-associated gastropod community after a series of drastically destructive nuclear tests, had cast important light on the process of natural recolonization of the impacted site. Yet some important additional enlightenements have been provided, here, thanks to:

(i) considering numerically extrapolated samplings - rather than basing only of the incomplete available samplings - which has highlighted to what extent considering numerically completed data (in terms of not only true species richness but also completed species abundance distribution including undected species) can deeply modify the appraisal of the process of recovery, thereby leading to more representative description and, especially, more sound and relevant interpretations;

(ii) making use of the notion of "standardized" abundance unevenness, rather than traditionally considering crude unevenness only. Standardized unevenness allows a more relevant appreciation of the socioecological significance of the uneven distribution of species abundances within community and, here also, favors more relevant interpretations of how incresing species is accommodated and how the hierarchic organization of species within community actually proceeds - dealing first with abiotic constraints only and, subsequently, with additional biotic mutual interactions eliciting more or less transient interspecific competition. Disentangling from each other these two main kinds of contributions to the uneven distribution of species abundances within species assemblages highlights the considerable advantage of partitionning the crude abundance unevenness in terms of its two complementary multiplicative contributions: (i) the species richness-related part on the one hand (relevantly conveyed by the corresponding broken-stick unevenness U') and (ii) the standardized unevenness "I $\mathrm{I}_{\text {str }}$ ", thus made formally independent of species-richness, on the other hand.

At last, as a highly significant by-product of this approach, strong empirical support (see Figs. 12, 13 \& Fig. A.1) has been provided to the MACARTHUR original conceptions, regarding the source and the ecological explanation of speciesabundance unevenness within communities, as being directly related to the patterns of the nicheassociated display. With the broken-stick model - characterising (sub-) nul competitive intensity no more serving as the universal model for species abundance distributions (as originally wrongly thought by MACARTHUR) but, quite more relevantly, offering a useful benchmark, against which to compare crude abundance unevenness - thereby offering a new, convenient approach for the estimation of the intensity of interspecific competition for shared resource at niche overlaps.

\section{ACKNOWLEDGEMENTS}

The author acknowledges the fruitful comments of two anonymous Reviewers.

\section{COMPETING INTERESTS}

Author has declared that no competing interests exist.

\section{REFERENCES}

1. Briggs JC. Marine biology: The role of accommodation in shaping marine biodiversity. Marine Biology. 2010;157 (10):2117-2126.

2. Graham JH, Duda JJ. The humpbacked species richness-curve: A contingent rule 
for community ecology. International Journal of Ecology. 2011;1-15.

3. Van de Perre F, Willig MR, Presley SJ, Mukinzi JC, et al. Functional volumes, niche packing and species richness: Biogeographic legacies in the Congo Basin. Royal Society Open Science. 2020;7:191582.

4. Heip CHR, Herman PMJ, Soetaert K. Indices of diversity and evenness. Océanis. 1998;24(4): 61-87.

5. Béguinot J. Theoretical derivation of a bias-reduced expression for the extrapolation of the Species Accumulation Curve and the associated estimation of total species richness. Advances in Research. 2016;7(3):1-16.

DOI:10.9734/AIR/2016/26387;<hal013678 03>

6. Béguinot J. Extrapolation of the species accumulation curve associated to "Chao" estimator of the number of unrecorded species: a mathematically consistent derivation. Annual Research \& Review in Biology. 2016;11(4):1-19.

DOI: 10.9734/ARRB/2016/30522; <hal $01477263>$

7. Béguinot J. How to extrapolate species abundance distributions with minimum bias when dealing with incomplete species inventories. Advances in Research. 2018; 13(4):1-24.

DOI: $10.9734 / A I R / 2018 / 39002$.

8. Lanctôt JL, Legendre P, Salvat B. How do coral reef Gastropods feel about nuclear blasts? A long-term study of the effects of man-made perturbations. Oceanologica Acta. 1997;20(1):243-257.

9. Legendre P, Salvat B. Thirty year recovery of mollusk communities after nuclear experimentations on Fangataufa atoll (Tuamotu, French Polynesia). Proceedings of the Royal Society B. 2015;282: 20150750.

10. Pianka EC. Niche overlap and diffuse competition. Proceedings of the National Academy of Sciences USA. 1974;71(5):2141-2145.

11. Schoener TW. Resource partitioning in ecological communities. Science. 1974;185:27-39.

12. Roughgarden J. Resource partitioning among competing species: A coevolutionary approach. Theoretical Population Biology. 1976;9(3):388-424.

13. Pacala $S \&$ Roughgarden J. Resource partitioning and interspecific competition in two two-species insular Anolis Lizard communities. Science. 1982;217:444-446.

14. Petchey L, Gaston KJ. Functional diversity (FD), species richness and community composition. Ecology Letters. 2002;5:402411.

15. Halpern BS, Floeter SR. Functional diversity responses to changing species richness in reef fish communities. Marine Ecology Progress Series. 2008;364:147156.

16. Dexiecuo A, Chengjin C, Farnon EMD, Rui $\mathrm{H}$, Gang W. Migration and niche partitioning simultaneously increase species richness and rarity. Ecological Modelling. 2013;258(C):33-39.

17. Li Y, Shipley B, Price JN, De Dantas V, Tamme $R$, Westoby $M$, et al. Habitat filtering determines the functional niche occupancy of plant communities worldwide. Journal of Ecology. 2018;106 (3):1001-1009.

18. Granot I, Belmaker J. Niche breadth and species richness: Correlation strength, scale and mechanisms. Global Ecology and Biogeography. 2019;00:1-12.

DOI: $10.1111 /$ geb.13011

19. Schoener TW. The evolution of bill size differences among sympatric congeneric species of birds. Evolution. 1965;19:185213.

20. Heck KL. Some critical considerations of the theory of species packing. Evolution Theory. 1976;1:247-258.

21. Pigot $\mathrm{AL}$, Trisos $\mathrm{CH}$, Tobias JA. Functional traits reveal the expansion and packing of ecological niche space underlying an elevational diversity gradient in passerine birds. Proceedings of the Royal society B. 2015;283:20152013.

22. Holt RD. On the relation between niche overlap and competition: the effect of incommensurable niche dimensions. Oikos. 1987;48(1):110.

23. Zhou SR, Zhang DY. Allee effects and the neutral theory of biodiversity. Functional Ecology. 2006;20:509-513.

24. Gascoigne J, Berec L, Gregory S, Courchamp F. Dangerously few liaisons: A review of mate-finding Allee effects. Population Ecology. 2009;51:355-372.

25. Bellier E, Grotan V, Engen S, Schartau AK, Diserud $\mathrm{OH}$, Finstad AG. Combining counts and incidence data: An efficient approach for estimating the log-normal species abundance distribution and diversity indices. Oecologia; 2012. 
DOI: 10.1007/s00442-012-2311-2.

26. Cam E, Nichols JD, Sauer JR, Hines JE. On the estimation of species richness based on the accumulation of previously unrecorded species. Ecography. 2002;25: 102-108.

27. Rajakaruna H, Drake DAR, Chan FT, Bailey SA. Optimizing performance of nonparametric species richness estimators under constrained sampling. Ecology and Evolution. 2016;6:7311-7322.

28. Connolly SR, Hughes TP, Bellwood DR. A unified model explains commonness and rarity on coral reefs. Ecology Letters. 2017; 20:477-486.

29. Chen Y, Shen TJ. Rarefaction and extrapolation of species richness using an area-based Fisher's logseries. Ecology and Evolution. 2017;7:10066-10078.

30. Kery M, Royle JA. Inference about species richness and community structure using species-specific occupancy models in the National Swiss Breeding Bird survey MUB. Proceedings of the 2007 EURING Technical Meeting and Workshop, Dunedin, New Zealand; 2007.

31. May RM. Patterns of species abundance and diversity. In Cody M.L. \& Diamond J.M. Ecology and evolution of communities. The Belknap Press of Harvard University. 1975;81-120.

32. Mc Gill BJ, Etienne RS, Gray JS et al. Species abundance distributions: Moving beyond single prediction theories to integration within an ecological framework. Ecology Letters. 2007;10:995-1015.

33. Ulrich W, Ollik M, Ugland KI. A metaanalysis of species-abundance distributions. Oikos. 2010; 119:1149-1155.

34. Komonen A, Elo M. Ecological response hides behind the species abundance distribution: Community response to lowintensity disturbance in managed grasslands. Ecology and Evolution. 2017; 7:8558-8566.

35. Wang X, Ellwood F, AI D, Zhang R, Wang G. Species abundance distributions as a proxy for the niche-neutrality continuum. Journal of Plant Ecology. 2017; rtx 013.

36. Chao A, Hsieh T, Chazdon RL, Colwell RK, Gotelli NJ. Unveiling the species-rank abundance distribution by generalizing the Good-Turing sample coverage theory. Ecology. 2015;96(5): 1189-1201.

37. Béguinot $J$. Numerical extrapolation of the species abundance distribution unveils the true species richness and the hierarchical structuring of a partially sampled marine gastropod community in the Andaman Islands (India). Asian Journal of Environment and Ecology. 2018; 6(4):123.

DOI: $\quad$ 10.9734/AJEE/2018/41293<hal01807454>

38. Strong WL. Assessing species abundance unevenness within and between plant communities. Community Ecology. 2002; 3(2): 237-246.

DOI: 10.1556/ComEc.3.2002.2.9

39. Magurran AE. The commonness and rarity of species. In Measuring Biological Diversity. Blackwell Publishing Ltd; 2004.

40. Grzès IM. Ant species richness and evenness increase along a metal pollution gradient in the Boleslaw zinc smelter area. Pedobiologia. 2009;53:65-73.

41. Smith B, Wilson JB. A consumer's guide to evenness indices. Oikos. 1996;76:7082.

42. Béguinot J. Disentangling and quantifying the functional determinants of species abundance unevenness in ecological communities. Advances in Research. 2019;19(1);1-14.

DOI: 10.9734/AIR/2019/v19i130114.

43. Mac Arthur RH. On the relative abundance of bird species. Proceedings of the National Academy of Sciences U.S.A. 1957;43:293-295.

44. Johnson MP, Raven PH. Natural regulation of plant species diversity. Evolutionary Biology. 1970;4:127-162.

45. Berger $\mathrm{WH}$, Parker FL. Diversity of planktonic Foraminifera in deep sea sediments. Science. 1970;168:1345-1347.

46. De Benedictis PA. On the correlations between certain diversity indices. The American Naturalist. 1973;107:295-302.

47. Stirling G, Wilsey B. Empirical relationships between species richness, evenness and proportional diversity. The American Naturalist. 2001;158(3):286-299.

48. Buzas MA, Hayek LAC. On richness and evenness within and between communities. Paleobiology. 2005;31(2): 199-220.

49. Loiseau N, Gaertner JC. Indices for assessing coral reef fish biodiversity: The need for a change in habits. Ecology and Evolution. 2015;5(18):4018-4027.

50. Röpke CP, Amadio S, Zuanon J, Ferreira EJG, Pereira de Deus C, Pires THS, Winemiller KO. Simultaneous abrupt shifts in hydrology and fish assemblage structure 
in a floodplain lake in the central Amazon. Scientific Reports. 2017;7:40170.

51. Béguinot J. The hierarchical structuring of species abundances within communities: disentangling the intensity of the underlying structuring process behind the apparent unevenness pattern. Advances in Research. 2018;16(1):1-12.

DOI: $10.9734 / A I R / 2018 / 43918$.

52. Su Q. A relationship between species richness and evenness that depends on specific relative abundance distribution. Peer J. 2018;6:e4951.

53. Béguinot J. The full hierarchical structuration of species abundances reliably inferred from the numerical extrapolation of still partial samplings: a case study with marine snail communities in Mannar Gulf (India). Asian Journal of Environment and Ecology. 2018;7(3):1-27. DOI: 109734/AJEE/2018/36831.

54. Béguinot J. Analyzing the role of environmental stresses on species richness and the process of hierarchical structuring of species abundances in marine Gastropods communities at Suva (Fiji Islands). International Journal of Environment and Climate Change. 2018; 8(3):200-233.

55. Béguinot J. Inferring total species richness and the exhaustive hierarchical structuring of species abundances in tropical SeaStars communities (Asteroidea), using numerical extrapolation of partial inventories. Asian Journal of Environment and Ecology. 2018;8(2):1-25.

DOI: 109734/AJEE/2018/46272.

56. Béguinot J. Comparing the complete hierarchical structuration of species abundances in reef fish communities according to coral morphology, using the numerical extrapolation of only incomplete inventories. Asian Journal of Environment and Ecology. 2018;8(1):1-20.

DOI: 109734/AJEE/2018/45402.

57. Béguinot J. Influence of coral architecture on species richness and the hierarchical structuration of species abundances in reef fish communities: A case study in the eastern tropical pacific. Asian Journal of Environment \& Ecology. 2018;8(3):1-21. DOI:https://doi.org/10.9734/ajee/2018/v8i3 30075

58. Béguinot J. Influence of fishing activity on the total species richness and the abundance unevenness in reef fish communities: a case study in a Brazilian tropical coral complex. International Journal of Environment and Climate Change. 2019;9(1):58-76.

59. Béguinot J. Influence of coral complexity on species richness and the hierarchical structuration of species abundances in reef fish communities: A case study in southeast Brazil. Asian Journal of Environment \& Ecology. 2019;9(3):1-20.

DOI: 10.9734/AJEE/2019/v9i330098.

60. Béguinot J. Influence of environmental heterogeneity on the species composition, species richness and species abundances unevenness in reef-associated Conus communities (Neogastropoda) from Papua New-Guinea. Asian Journal of Environment \& Ecology. 2019; 10(3):1-21. DOI: 10.9734/AJEE/2019/v10i330116.

61. Béguinot J. Variations in total species richness and the unevenness of species abundance distribution between two distant Conus communities (Neogastropoda) : A case study in Mannar Gulf (India). Asian Journal of Environment \& Ecology. 2019;9(4):1-18.

DOI: 10.9734/AJEE/2019/v9i430102.

62. Béguinot J. Inferring true species richness and complete abundance distribution in six reef-fish communities from Red-Sea, using the numerical extrapolation of incomplete samplings. Asian Journal of Environment \& Ecology. 2019;11(3):1-21.

DOI: 10.9734/AJEE/2019/v11i330136.

63. Planes S, Galzin R, Bablet JP a Sales PF. Stability of coral reef fish assemblages impacted by nuclear tests. Ecology. 2005;86(10):2578-2585.

64. Richards ZT, Beger M, Pinca S \& Wallace CC. Bikini atoll coral biodiversity resilience five decades after nuclear testing. Marine Pollution Bulletin. 2008;56:503-515.

65. MacArthur RH. Note on Mrs Pielou's comments. Ecology. 1966;47:1074.

66. Wilson JB. Would we recognize a BrokenStick community if we found one? Oikos. 1993; 67(1):81-183.

67. Loreau M. Species abundance patterns and the structure of ground-beetle communities. Ann. Zool. Fennici. 1992;28:49-56.

68. Magurran AE, Henderson PA. Explaining the excess of rare species in natural species abundance distributions. Nature. 2003;422:714-716.

69. Connolly SR, Hughes TP, Bellwood DR, Karlson $\mathrm{RH}$. Community structure of corals 
and reef fishes at multiple scales. Science. 2005;309:1363-1365.

70. Ulrich W, Soliveres S, Thomas AD, Dougill AJ, Maestre FT. Environmental correlates of species rank-abundance distributions in global drylands. Europe PMC Funders Group. 2016;20:56-64.

71. Chacon-Labella J, de la Cruz M, Escudero A. Evidence for a stochastic geometry of biodiversity: The effects of species abundance, richness and intraspecific clustering. Journal of Ecology. 2017;105: 382-390.

72. Baldridge E, Harris DJ, Xiao X, White EP. An extensive comparison of species abundance distribution models. PeerJ. 2016;4e2823.

DOI: doi 10.7717/peerj.2823

73. Béguinot J. An algebraic derivation of Chao's estimator of the number of species in a community highlights the condition allowing Chao to deliver centered estimates. ISRN Ecology; 2014.

Article ID: 847328,

DOI:10.1155/2014/847328; <hal01101415>

74. Béguinot J. When reasonably stop sampling? How to estimate the gain in newly recorded species according to the degree of supplementary sampling effort. Annual Research \& Review in Biology. 2015;7(5):300-308;

DOI: 10.9734/ARRB/2015/18809; <hal01228695>

75. Béguinot J. On general mathematical constraints applying to the kinetics of species discovery during progressive sampling: Consequences on the theoretical expression of the Species
Accumulation Curve. Advances in Research. 2016;8(5):1-17.

76. $\mathrm{Li} \mathrm{CT}, \mathrm{Li} \mathrm{KH}$. Species abundance distribution and species accumulation curve: A general framework and results. arXiv. 2020;2011.07270v1 [stat.AP].

77. Menegotto A, Rangel TF. Mapping knowledge gaps in marine diversity reveals a latitudinal gradient of missing species richness. Nature communications. 2018;9: 4713.

DOI: 10.1038/s41467-018-07217-7.

78. O'Hara RB. Species richness estimators: how many species can dance on the head of a pin? Journal of Animal Ecology. 2005; 74:375-386.

79. Gotelli NJ, Colwell RK. Estimating species richness. in: Biological diversity: Frontiers in measurement and assessment. A.E. Magurran and B.J. McGill (eds.), Oxford University Press, Oxford. 2010;39-54.

80. Gotelli NJ, Chao A. Measuring and estimating species richness, species diversity and biotic similarity from sampling data. In: Levin S.A. (ed.) Encyclopedia of Biodiversity, second edition; Waltham, MA: Academic Press. 2013,5:195-211.

81. Bevilacqua S, Ugland $\mathrm{KI}$, Plicanti A, Scuderi D, Terlizzi A. An approach based on the total-species accumulation curve and higher taxon richness to estimate realistic upper limits in regional species richness. Ecology and Evolution. 2018; 8:405-415.

82. Brose U, Martinez ND, Williams RJ. Estimating species richness: Sensitivity to sample coverage and insensitivity to spatial patterns. Ecology, 2003;84(9):23642377. 


\section{APPENDIX 1}

About the relevance of the ecological interpretation, by MACARTHUR, of niches-display patterns and the associated species-abundance distribution

The role of the "broken-stick" distribution as a model apt to be almost universally fitted by most (if not all) empirical Species Abundance Distributions - as originally suggested by MACARTHUR [43] (1957) has been largely refuted subsequently and its inadequacy in this particular respect has been recognized later on by MACARTHUR himself [65]. Some doubt has also been cast by a few authors as regards the association of the "broken-stick" model to the "contiguous non-overlapping niches" pattern, stated by MACARTHUR [43]. The issue is, admittedly, a complex matter, not so easy to decide from a purely theoretical point of view. Yet, growing empirical evidence now accumulates to support the "broken-stick" distribution as being clearly central, when considering how co-occurring species do structure their relative abundances within natural communities.

A first aspect of this growing empirical evidence is presented in Fig. A.1, established using data from 37 tropical, marine communities (the present study and data from references [37, 53-62]). Although not being a full demonstration, this piece of evidence looks rather convincing, when considering both:

(i) the remarkable parallelism between the broken-stick unevenness $U^{\prime}\left(S_{t}\right)$ and the overall trend for decrease of the crude unevenness $U$ with species richness $S_{t}$ and

(ii) more precisely, the position of $U^{\prime}\left(S_{t}\right)$ as a "baseline" for the distribution of crude unevenness values $\mathrm{U}$ for the 37 marine communities - a basal position which fairly well complies with the conception of the 'broken-stick' distribution as resulting from the "contiguous, non-overlapping niches" pattern, proposed by MACARTHUR [43]. This indeed provides strong support to the functional significance of the broken-stick distribution [66] and, accordingly, gives credit to the relevance of considering the broken-stick abundance unevenness $U^{\prime}\left(S_{t}\right)$ and the related standardized unevenness index $\mathrm{I}_{\mathrm{str}}$, as appropriate tools to provide functional, ecologically sound, interpretations of the Species Abundance Distribution within natural communities.

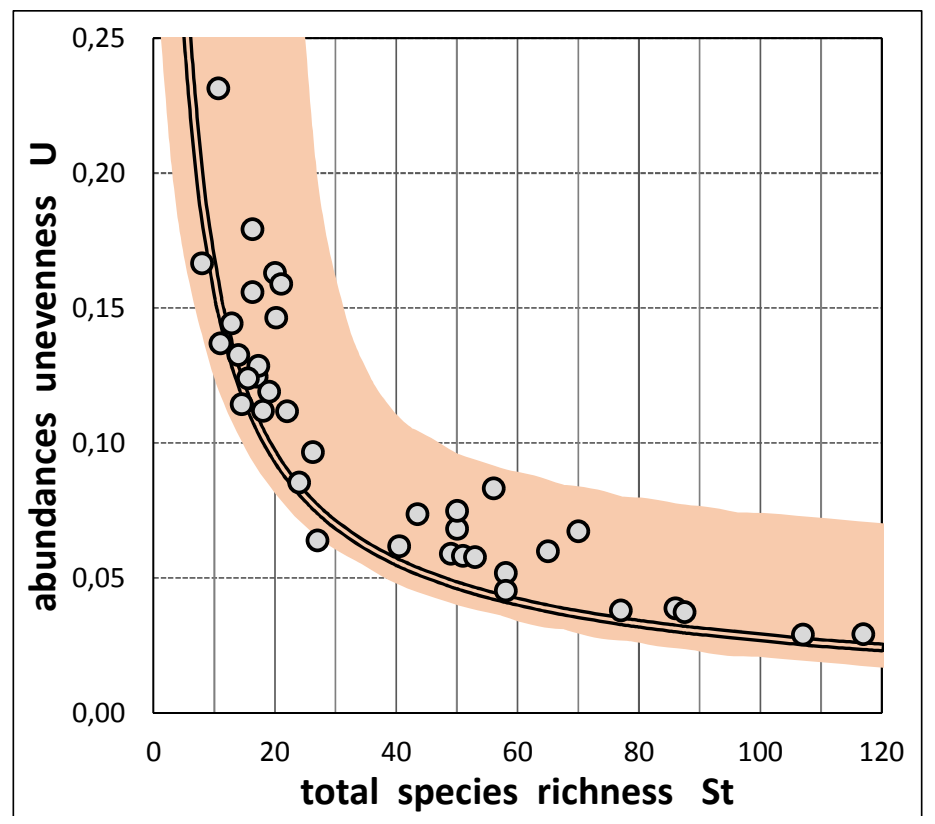

Fig. A1. Species abundance unevenness $U=\log _{10}\left(a_{1} / a_{s t}\right) /\left(S_{t}-1\right)$ in 37 marine communities (grey discs) - and for comparison the computed abundance unevenness $U^{\prime}\left(S_{t}\right)$ for the 'broken-stick' distribution (double line) - both plotted against species richness $\mathbf{S}_{\mathbf{t}}$. 


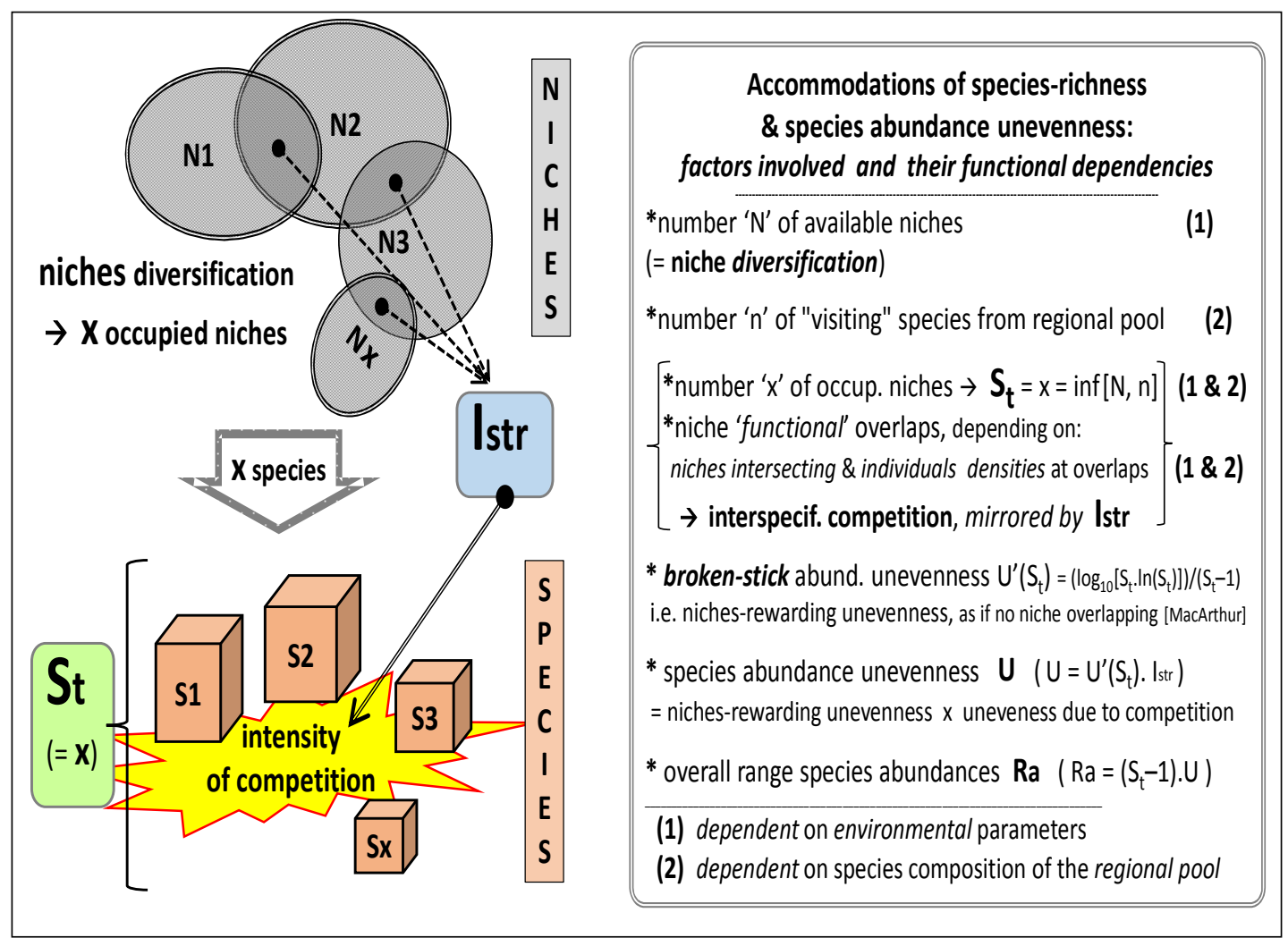

Box 1. Schematic representation of how the accommodations of both species-richness and species abundance unevenness are partially (i) inter-dependent and (ii) dependent on (ii.a) the environmental parameters and (ii.b) the composition of the regional pool of species. Species richness ' $\mathrm{S}_{\mathrm{t}}$ ' and the standardized unevenness ' $\mathrm{str}_{\mathrm{str}}$ ' are the two main (and mutually independent) descriptive and functional factors which, by themselves alone, suffice to characterize important quantitative aspects ruling the internal organization of species within communities. Two additional, subordinate factors, the crude abundance unevenness $U$ and the overall range of species abundances $R_{\mathrm{a}}$ are, for their own, entirely dependent upon the formers, $S_{t}$ and $I_{s t r}$. The broken-stick abundance unevenness $U^{\prime}\left(S_{t}\right)$ - due to its meaningful linkage with the "non-overlapping niches display" [43] - thereby plays the role of a sort of "compass" supporting the relevant functional interpretation of the "hierarchical" organization among co-occurring species within community.

Important remark - There is growing agreement in favor of the "log-normal" distribution being the best fitted model for most empirical Species Abundance Distributions [42,67-71]. The "log-series" distribution, although still recently advocated [72], being more appropriate to fit incomplete, therefore artificially truncated Species Abundance Distributions, lacking the subset of less abundant species, as a result of partial samplings [42,67-70]. The focal role given to the "broken-stick" distribution - yet not cited above - could thus seem incongruous, at first sight. Yet, in fact, the "broken-stick" does share with the "log-normal" a same, basically stochastic process of generation, resulting from the contributive combinations of multiple, statistically mutually independent events. With the difference that the number of stochastic events involved in the "broken-stick" process is, by essence, fewer than is the virtual infinity of stochastic events ideally involved in the "log-normal" process. But, in practice and due to its similar ontogeny, the "broken-stick" distribution actually merges fairly well into the "lognormal" family. This, indeed, may be easily verified empirically, as soon as species richness is greater than $\approx 10$. Figure $A 2$ provides just an illustrative example for $S_{t}=60$. 


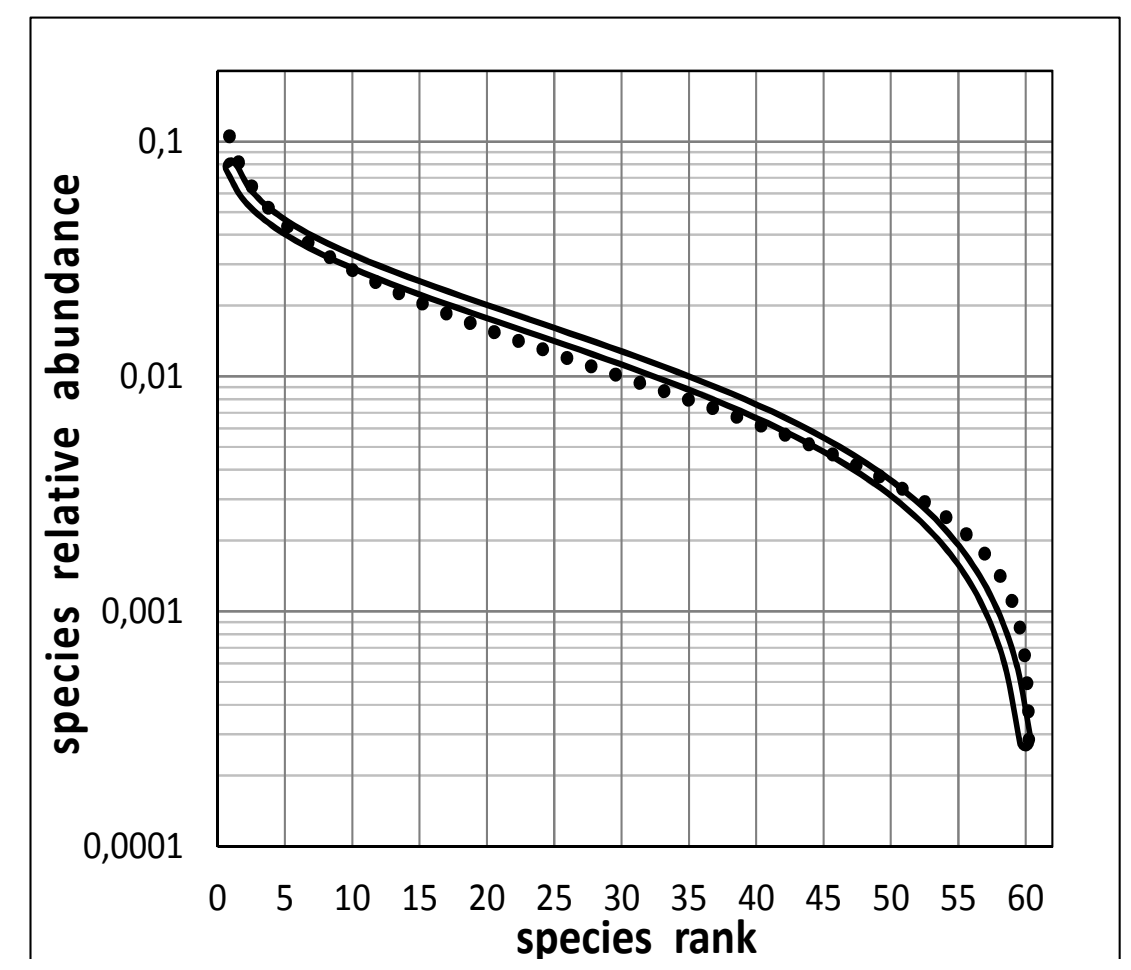

Fig. A2. The "broken-stick" distribution (here for species richness St = 60: double line) fits reasonably well the log-normal distribution computed, for the same species richness, with a particular standard deviation $=0.46$ (dotted curve)

\section{APPENDIX 2}

Bias-reduced extrapolation of the Species Accumulation Curve and the associated estimation of the number of missing species, based on the recorded numbers of species occurring 1 to 5 times

Consider the survey of an assemblage of species of size $N_{0}$ (with sampling effort $N_{0}$ typically identified either to the number of recorded individuals or to the number of sampled sites, according to the inventory being in terms of either species abundances or species incidences), including $R\left(N_{0}\right)$ species among which $f_{1}, f_{2}, f_{3}, f_{4}, f_{5}$, of them are recorded $1,2,3,4,5$ times respectively. The following procedure, designed to select the less-biased solution, results from a general mathematical relationship that constrains the theoretical expression of any theoretical Species Accumulation Curves $R(N)$ (see $[5,6,73-76])$ :

$$
\partial^{\mathrm{x}} \mathrm{R}_{(\mathrm{N})} / \partial \mathrm{N}^{\mathrm{x}}=(-1)^{(\mathrm{x}-1)} \mathrm{f}_{\mathrm{x}(\mathrm{N})} / \mathrm{C}_{\mathrm{N}, \mathrm{x}} \approx(-1)^{(\mathrm{x}-1)}\left(\mathrm{x} ! / \mathrm{N}^{\mathrm{x}}\right) \mathrm{f}_{\mathrm{x}(\mathrm{N})} \quad(\approx \text { as } \mathrm{N}>>\mathrm{x})
$$

Compliance with the mathematical constraint (equation (A.1)) warrants reduced-bias expression for the extrapolation of the Species Accumulation Curves $R(N)$ (i.e. for $N>N_{0}$ ). Below are provided, accordingly, the polynomial solutions $R_{x}(N)$ that respectively satisfy the mathematical constraint (A1.1), considering increasing orders $x$ of derivation $\partial^{x} R_{(N)} / \partial N^{x}$. Each solution $R_{x}(N)$ is appropriate for a given range of values of $f_{1}$ compared to the other numbers $f_{x}$, according to [5]:

$$
\begin{aligned}
& { }^{*} \text { for } \mathrm{f}_{1} \text { up to } \mathrm{f}_{2} \rightarrow \mathrm{R}_{1}(\mathrm{~N})=\left(\mathrm{R}\left(\mathrm{N}_{0}\right)+\mathrm{f}_{1}\right)-\mathrm{f}_{1} \cdot \mathrm{N}_{0} / \mathrm{N} \\
& \text { * for larger } f_{1} \text { up to } 2 f_{2}-f_{3} \rightarrow R_{2}(N)=\left(R\left(N_{0}\right)+2 f_{1}-f_{2}\right)-\left(3 f_{1}-2 f_{2}\right) \cdot N_{0} / N- \\
& \left(f_{2}-f_{1}\right) \cdot N_{0}^{2} / N^{2}
\end{aligned}
$$




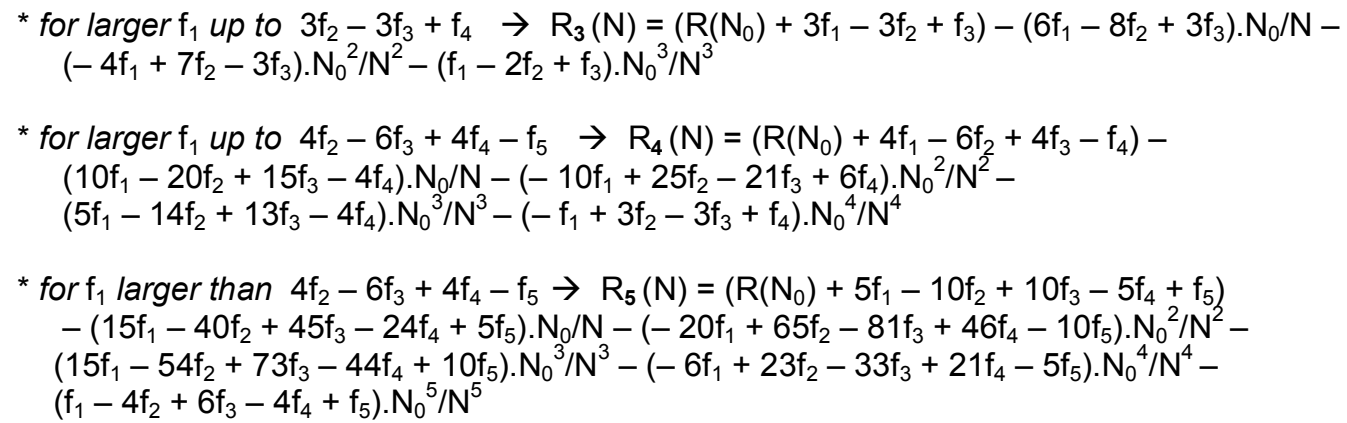

The associated non-parametric estimators of the number $\Delta_{\mathrm{J}}$ of missing species in the sample [with $\Delta_{\mathrm{J}}$ $\left.=R(N=\infty)-R\left(N_{0}\right)\right]$ are derived immediately:

$$
\begin{aligned}
& { }^{*} \mathrm{f}_{1} \leq \mathrm{f}_{2} \quad \rightarrow \quad \Delta_{\mathrm{J} 1}=\mathrm{f}_{1} ; \mathrm{R}_{1}(\mathrm{~N}) \\
& { }^{*} \mathrm{f}_{2}<\mathrm{f}_{1} \leq 2 \mathrm{f}_{2}-\mathrm{f}_{3} \rightarrow \Delta_{\mathrm{J} 2}=2 \mathrm{f}_{1}-\mathrm{f}_{2} ; \mathrm{R}_{2}(\mathrm{~N}) \\
& \text { * } 2 f_{2}-f_{3}<f_{1} \leq 3 f_{2}-3 f_{3}+f_{4} \rightarrow \Delta_{J 3}=3 f_{1}-3 f_{2}+f_{3} ; \quad R_{3}(N) \\
& \text { * } 3 f_{2}-3 f_{3}+f_{4}<f_{1} \leq 4 f_{2}-6 f_{3}+4 f_{4}-f_{5} \rightarrow \quad \Delta_{J 4}=4 f_{1}-6 f_{2}+4 f_{3}-f_{4} ; \quad R 4(N) \\
& { }^{*} f_{1}>4 f_{2}-6 f_{3}+4 f_{4}-f_{5} \rightarrow \Delta_{J 5}=5 f_{1}-10 f_{2}+10 f_{3}-5 f_{4}+f_{5} ; \quad R_{5}(N)
\end{aligned}
$$

N.B. 1: As indicated above (and demonstrated in details in [5]), this series of inequalities define the ranges that are best appropriate, respectively, to the use of each of the five estimators, JK-1 to JK-5. That is the respective ranges within which each estimator will benefit of minimal bias for the predicted number of missing species.

Besides, it is easy to verify that another consequence of these preferred ranges is that the selected estimator will always provide the highest estimate, as compared to the other estimators. Interestingly, this mathematical consequence, of general relevance, is in line with the already admitted opinion that all non-parametric estimators provide more or less pronounced under-estimates of the true number of missing species $[27,29,77-81]$. Also, this shows that the approach initially proposed in [82] - which has regrettably suffered from its somewhat difficult implementation in practice - might be advantageously reconsidered, now, in light of the very simple selection key above, of far much easier practical use. Namely: the best estimate of the number of species remaining unrecorded after incomplete sampling is provided by the non-parametric estimator providing the highest value, among the Chao and the series of Jackknife estimators. And this is not only a likely admissible point of view, as suggested in [27,29,77-81], but, now, a rationally established affirmation.

N.B. 2: In order to reduce the influence of drawing stochasticity on the values of the $f_{x}$, the asrecorded distribution of the $f_{x}$ should preferably be smoothened: this may be obtained either by rarefaction processing or by regression of the as-recorded distribution of the $f_{x}$ versus $x$.

N.B. 3: For $f_{1}$ falling beneath $0.6 \times f_{2}$ (that is when sampling completeness closely approaches exhaustivity), then Chao estimator may alternatively be selected: see reference [6]. 


\section{APPENDIX 3}

\section{Correction and extrapolation (when required) of the as-recorded S.A.D.}

N.B.: details regarding the derivation of the following expressions are provided in [7].

1) Correction for bias of the recorded part of the S.A.D.

The bias-corrected expression of the true abundance, $\tilde{a}_{i}$, of species of rank ' $i$ ' in the S.A.D. is given by:

$$
\tilde{a}_{i}=p_{i \cdot} \cdot\left(1+1 / n_{i}\right) /\left(1+R_{0} / N_{0}\right) \cdot\left(1-f_{1} / N_{0}\right)
$$

Where $\mathrm{N}_{0}$ is the actually achieved sample size, $\mathrm{R}_{0}\left(=\mathrm{R}\left(\mathrm{N}_{0}\right)\right)$ the number of recorded species, among which a number $f_{1}$ are singletons (species recorded only once), $n_{i}$ is the number of recorded individuals of species ' $i$ ', so that $p_{i}=n_{i} / N_{0}$ is the recorded frequency of occurrence of species ' $i$ ', in the sample. The crude recorded part of the "S.A.D." - expressed in terms of the series of as-recorded frequencies $p_{i}=n_{i} / N_{0}$ - should then be replaced by the corresponding series of expected true abundances, $\tilde{a}_{i}$, according to equation (A2.1).

2) Extrapolation of the recorded part of the S.A.D. accounting for the complementary abundance distribution of the set of unrecorded species

The following expression stands for the estimated abundance, $a_{i}$, of the unrecorded species of rank $i$ (thus for $\mathrm{i}>\mathrm{R}_{0}$ ):

$$
a_{i}=\left(2 / N_{i}\right) /\left(1+R\left(N_{i}\right) / N_{i}\right) \cdot\left(1-[\partial R(N) / \partial N]_{N i}\right)
$$

Which, in practice, comes down to: $a_{i} \approx\left(2 / N_{i}\right) /\left(1+R\left(N_{i}\right) / N_{i}\right)$, as $f_{1}(N)$ already becomes quite negligible as compared to $\mathrm{N}$ for the extrapolated part.

This equation provides the extrapolated distribution of the species abundances $a_{i}$ (for $i>R\left(N_{0}\right)$ ) as a function of the least-biased expression for the extrapolation of the species accumulation curve $R(N)$ (for $N>N_{0}$ ), 'i' being equal to $R\left(N_{i}\right)$. The key to select the least-biased expression of $R(N)$ is provided at Appendix 2.

\section{APPENDIX 4}

\section{Derivation of the expression of the abundance unevenness $U^{\prime}\left(S_{t}\right)$ of the broken-stick distribution}

The derivation of the expression for U'( $\left.S_{t}\right)$ proceeds from reference [31] by MAY. In his Table 3, within reference [31], MAY defines the dominance ' $d$ ' in the broken-stick distribution as $d=\ln \left(S_{t}\right) / S_{t}($ at least for $S_{t}$ not too low, say > 10). As the dominance is defined as the higher relative abundance, namely $a_{1}{ }_{1}$ in the broken-stick, it comes:

$$
a_{1}^{\prime}=\ln \left(S_{t}\right) / S_{t}
$$

Then, ' $J$ ', the inverse of the lowest relative abundance $a_{S t}$ (his equations (1.1)) is identified to $S_{t}^{2}$ (his equation (D.6)), so that:

$a^{\prime}{ }_{S t}=1 / S_{t}^{2}$

And thus:

$$
\begin{aligned}
& a_{1}^{\prime} / a^{\prime}{ }_{S t}=\left[\ln \left(S_{t}\right) / S_{t}\right] /\left(1 / S_{t}{ }^{2}\right)=S_{t} \cdot \ln \left(S_{t}\right) \\
& \text { Accordingly, from the definition of } U^{\prime}(S t): \\
& \left.U^{\prime}(S t)=\log _{10}\left(a^{\prime}{ }_{1} / a^{\prime}{ }_{S t}\right)\right] /\left(S_{t}-1\right) \\
& \text { it comes finally: } \\
& U^{\prime}(S t)=\left(\log _{10}\left[S_{t} \cdot \ln \left(S_{t}\right)\right]\right) /\left(S_{t}-1\right)
\end{aligned}
$$




\section{APPENDIX 5}

Demonstration that the overall range $R_{a}$ of species abundances is strongly related to the level of the lowest abundance $a_{\text {st }}$

For the purpose of demonstration, let consider an assemblage of species with a species abundance distribution ideally fitting a geometric series with a constant ratio ' $k$ ' $=a_{i} / a_{i+1}$ between two successive species, $i$ and $i+1$, ranked by decreasing values of abundance. It comes, for the most and the least abundant species $\mathrm{a}_{1}$ and $\mathrm{a}_{\mathrm{St}}$ :

$$
a_{1}=\left(k^{S t}-k^{S t-1}\right) /\left(k^{S t}-1\right) \text { and } a_{S t}=(k-1) /\left(k^{S t}-1\right)
$$

Then:

$$
\begin{aligned}
& \partial \mathrm{a}_{1} / \partial \mathrm{S}_{\mathrm{t}}=-(\mathrm{k}-1) \cdot \mathrm{k}^{\mathrm{St}-1} \cdot \ln (\mathrm{k}) /\left(\mathrm{k}^{\mathrm{St}}-1\right)^{2} \\
& \partial \mathrm{a}_{\mathrm{St}} / \partial \mathrm{S}_{\mathrm{t}}=-(\mathrm{k}-1) \cdot \mathrm{k}^{\mathrm{St}} \cdot \ln (\mathrm{k}) /\left(\mathrm{k}^{\mathrm{St}}-1\right)^{2}
\end{aligned}
$$

And

$$
\begin{aligned}
& \partial \ln \left(a_{1}\right) / \partial S_{t}=\left(1 / a_{1}\right) \cdot \partial a_{1} / \partial S_{t}=-\ln (k) /\left(k^{S t}-1\right) \\
& \partial \ln \left(a_{S t}\right) / \partial S_{t}=\left(1 / a_{S t}\right) \cdot \partial a_{S t} / \partial S_{t}=-k^{S t} \cdot \ln (k) /\left(k^{S t}-1\right)
\end{aligned}
$$

Thus:

$$
\partial \ln \left(a_{S t}\right) / \partial S_{t}=k^{S t} . \partial \ln \left(a_{1}\right) / \partial S t
$$

As soon as $k>1, k^{S t}$ rapidly exceeds unity, considering usual values of species richness $S_{t}$. It follows that $\ln \left(a_{\mathrm{St}}\right)$ decreases much faster with species richness than does $\ln \left(\mathrm{a}_{1}\right)$. In practice, as soon as $\mathrm{k}>$ 1.07, $\ln \left(a_{1}\right)$ remains substantially constant while $\ln \left(a_{S t}\right)$ steadily decreases rapidly with increasing species richness.

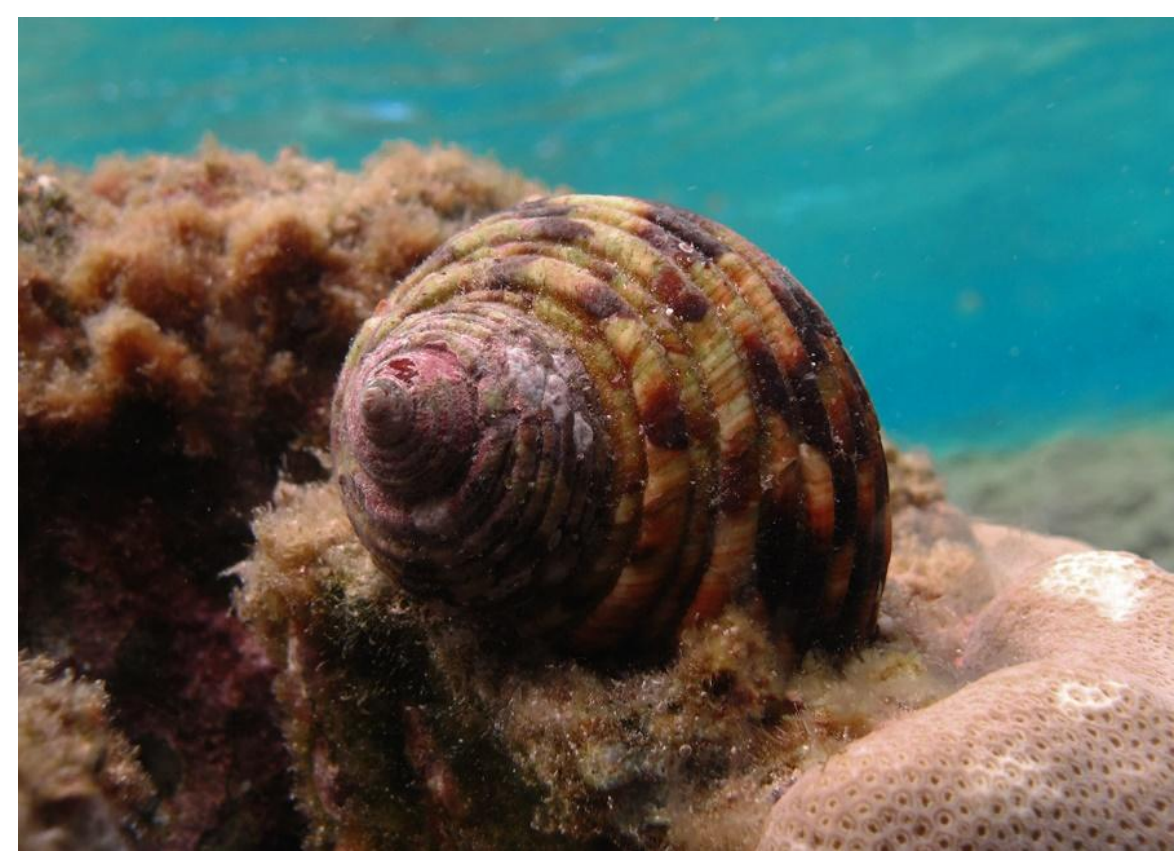

Picture 1. [A] -Turbo setosus Gmelin, 1791 @ Ph. Bourjon 


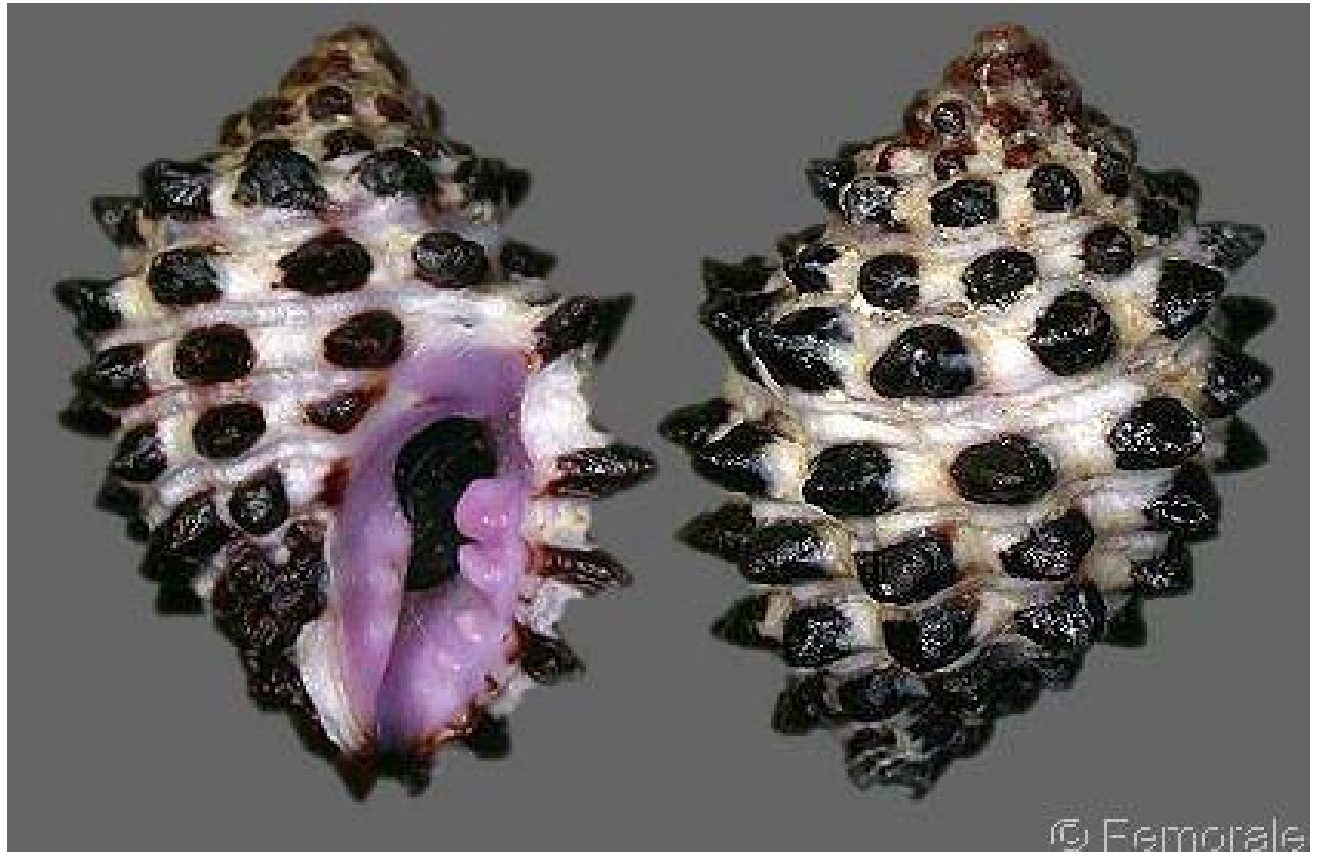

Picture 2. [A]. Morula uva Röding, 1798 @ Femorale

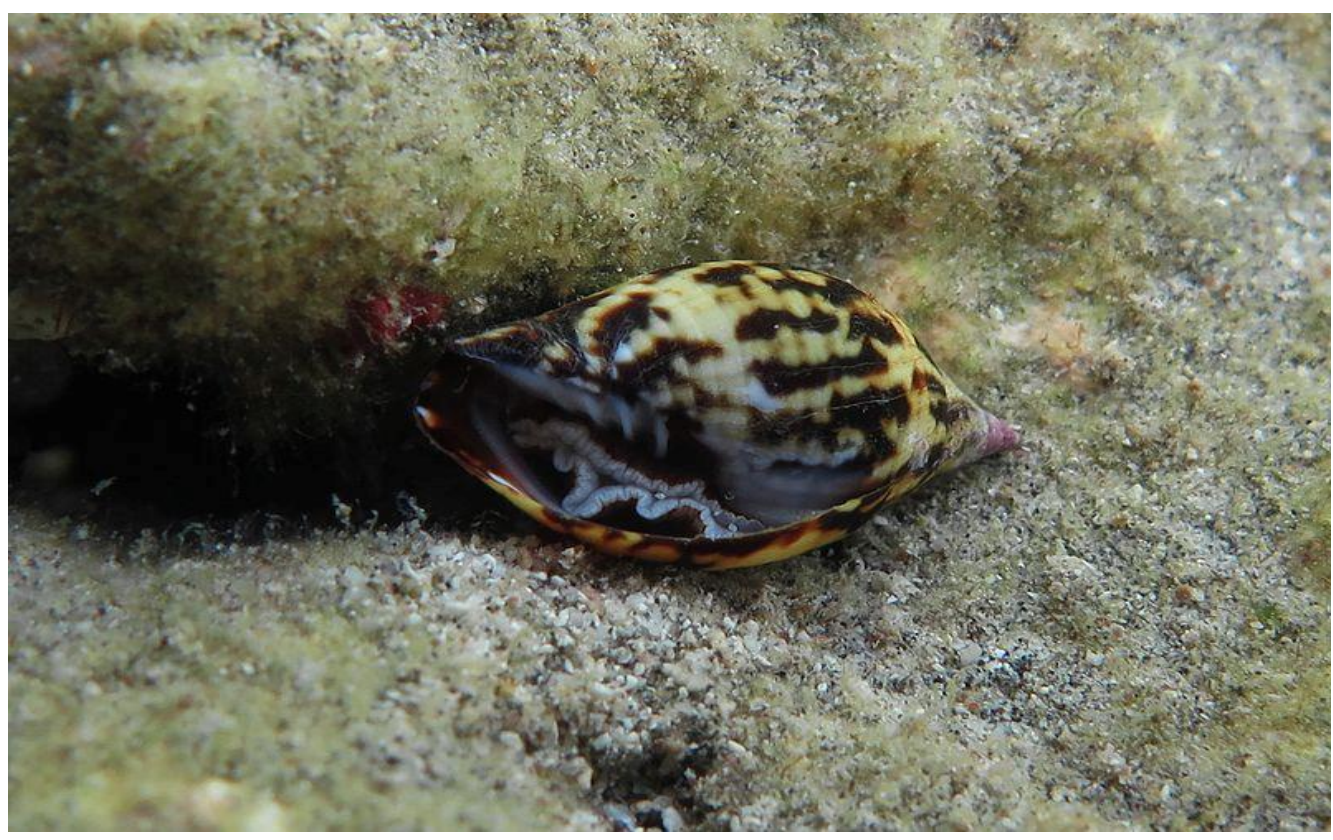

Picture 3. [A]. Mitra litterata Lamarck, 1811 @ Ph. Bourjon 


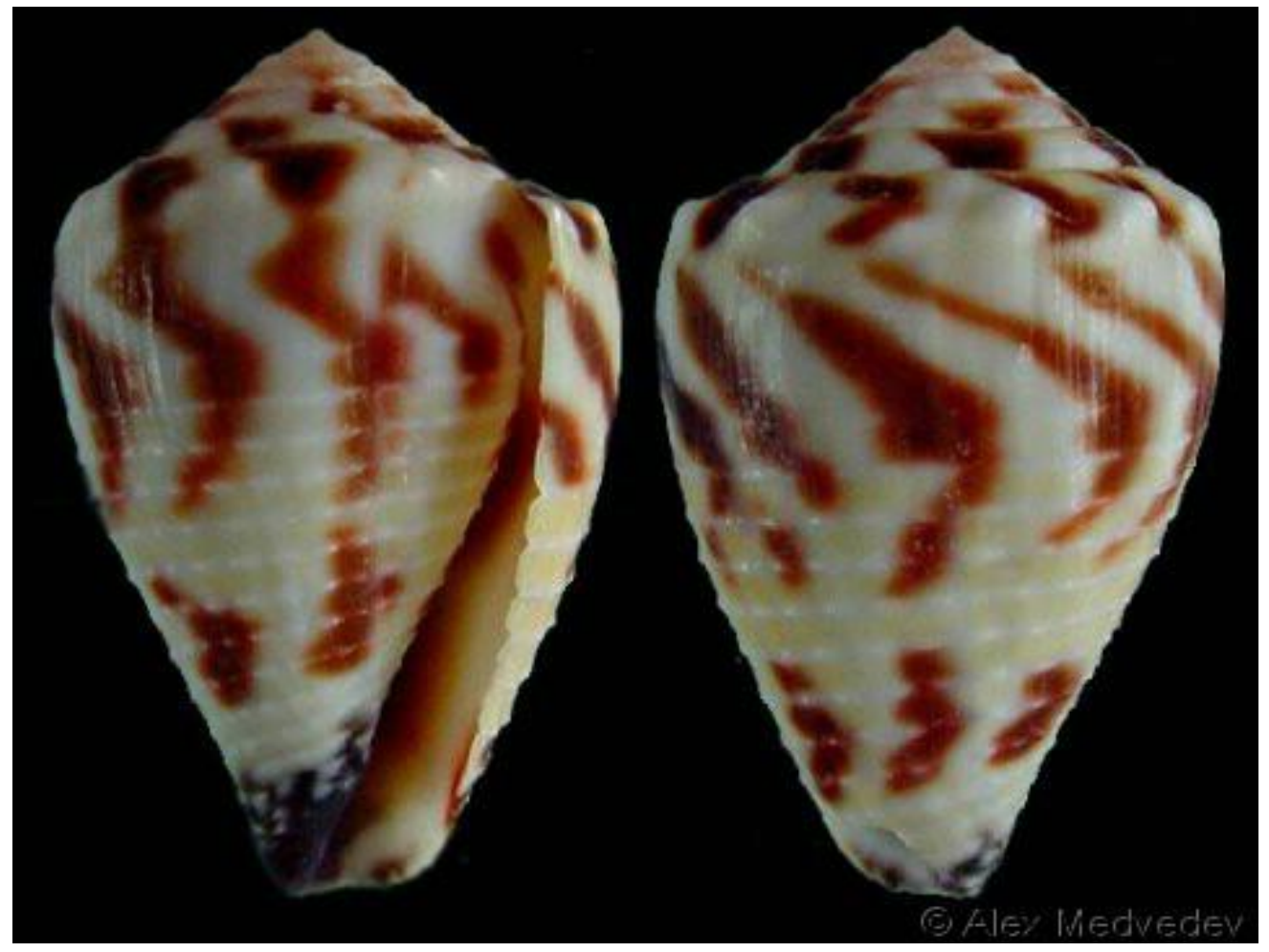

Picture 4. [A] . Conus sponsalis Hwass in Bruguière 1792 @ Alex Medvedev

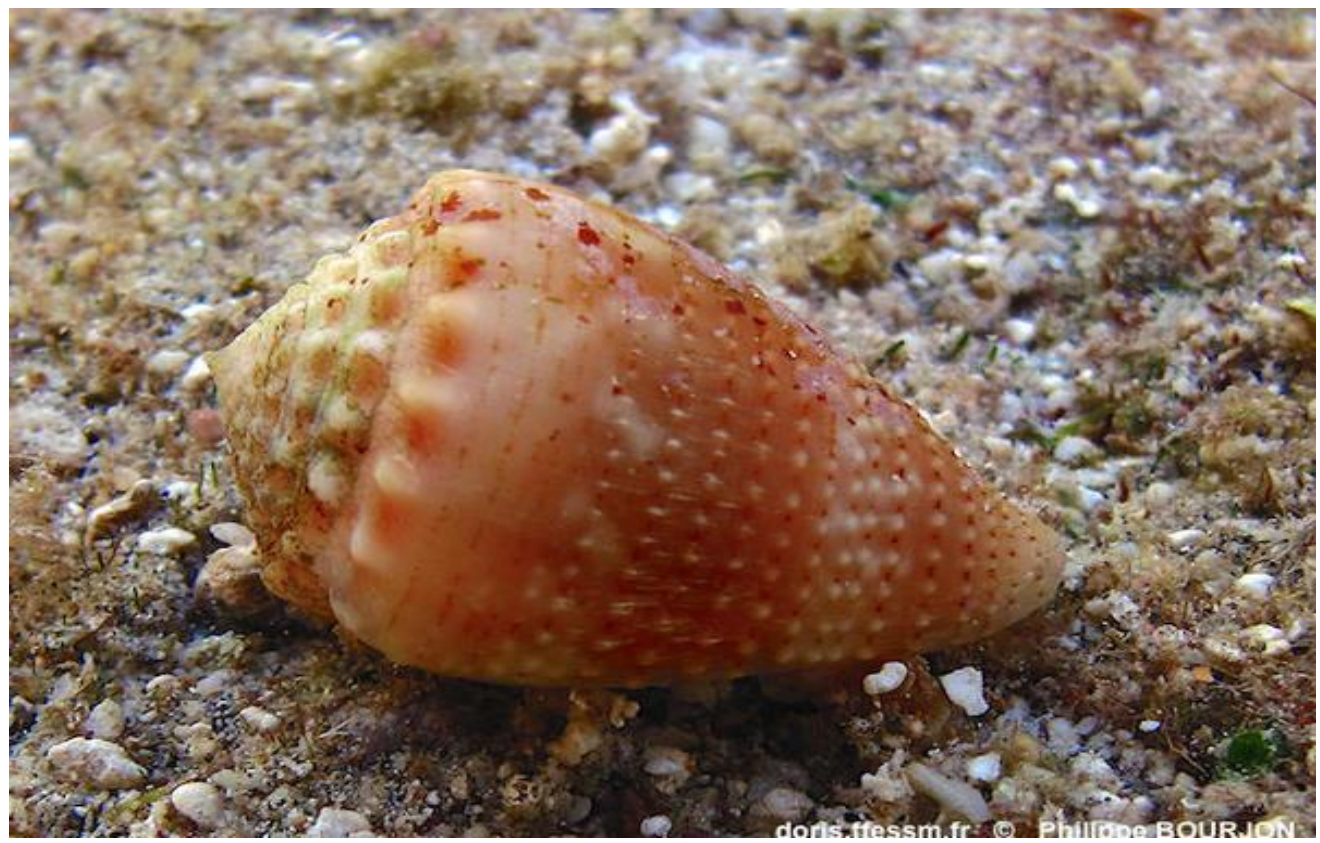

Picture 5. [A] . Conus miliaris Hwass in Bruguière 1792 ( Ph. Bourjon 


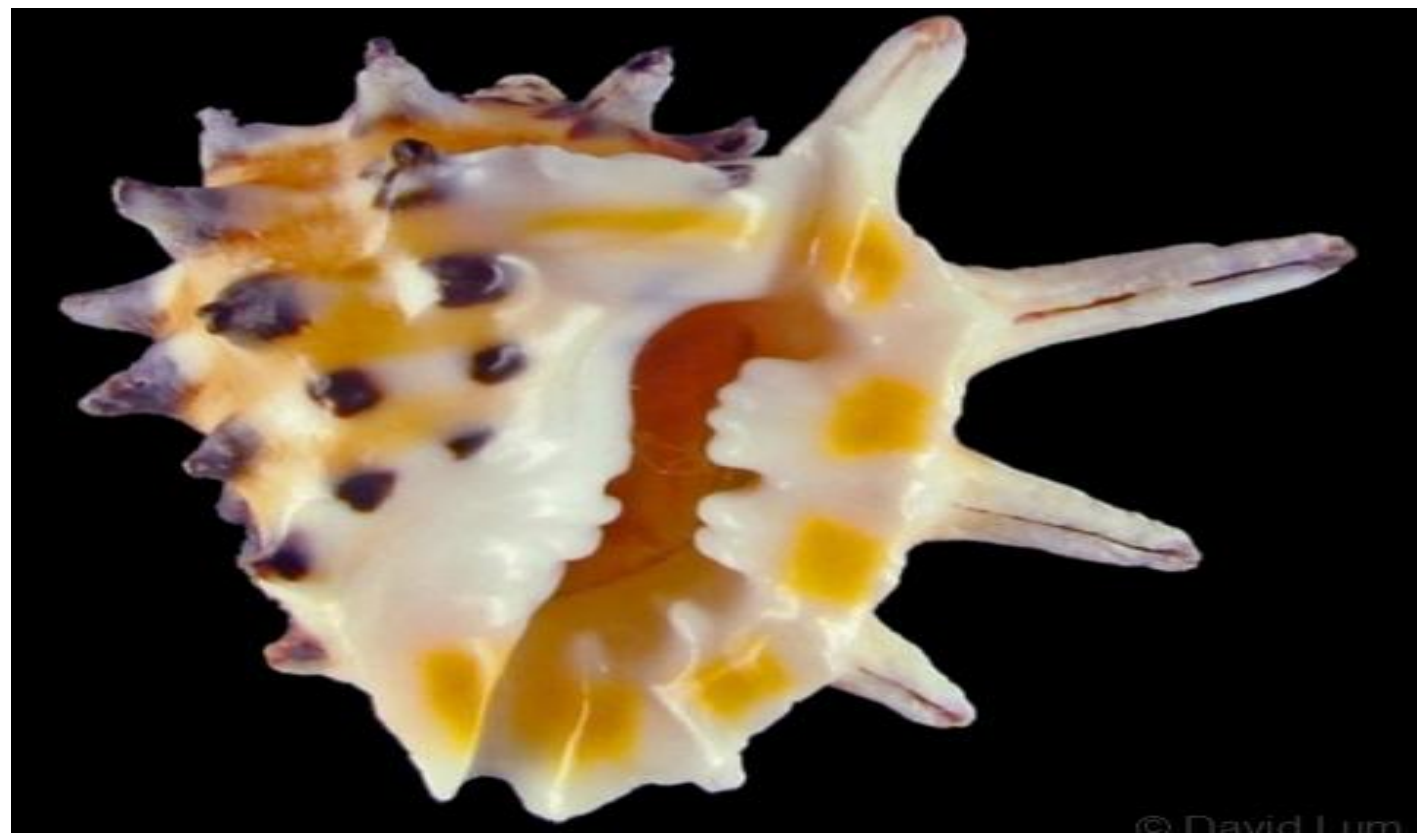

Picture 6. [A]. Drupa ricinus Linnaeus, 1758 @ David Lum

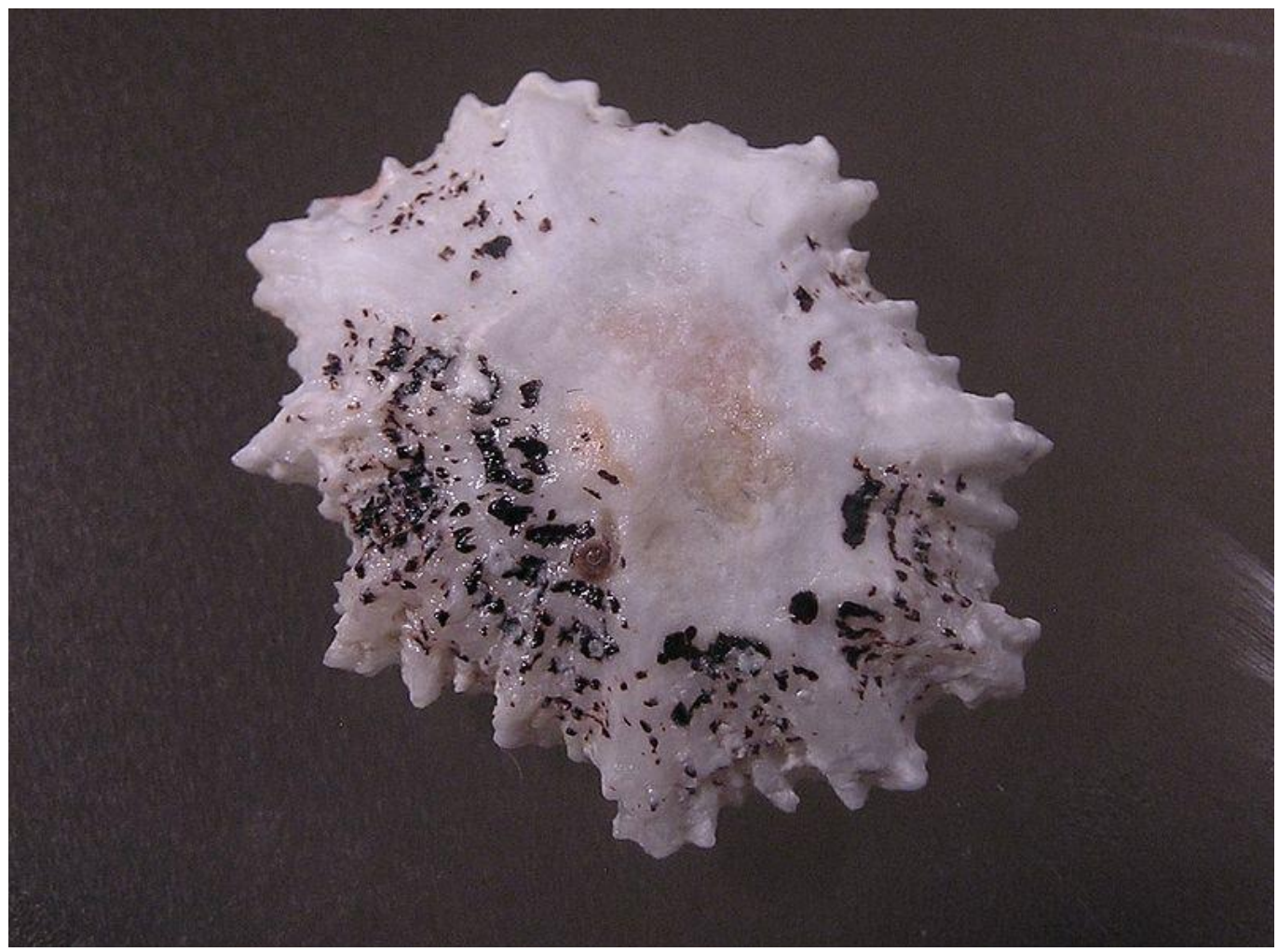

Picture 7. [B] . Patella flexuosa Quoy \& Gaimard 1834 @ Jan Delsing 


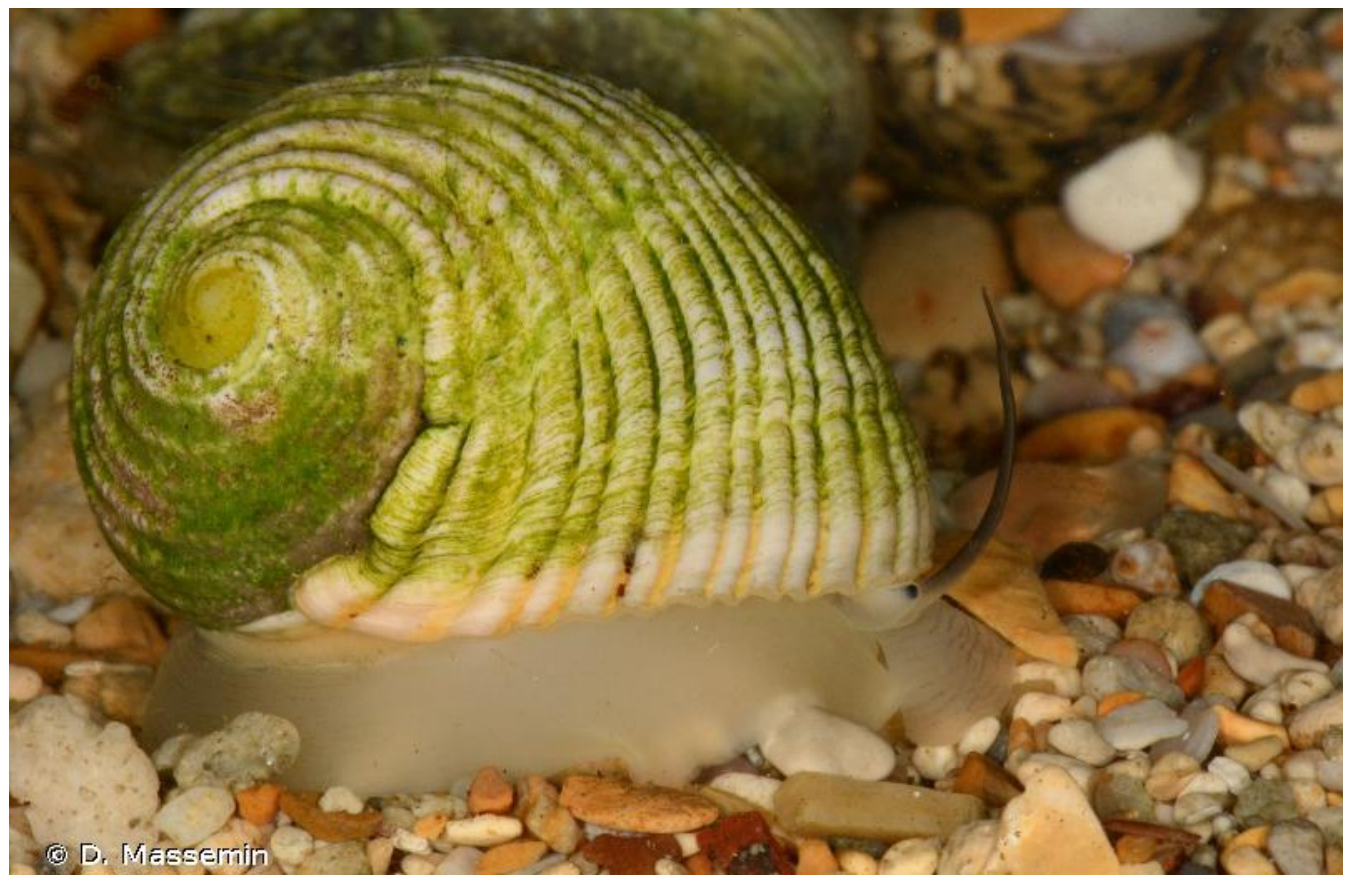

Picture 8. [C] . Nerita plicata Linnaeus, 1758 @ D. Massemin MNHN

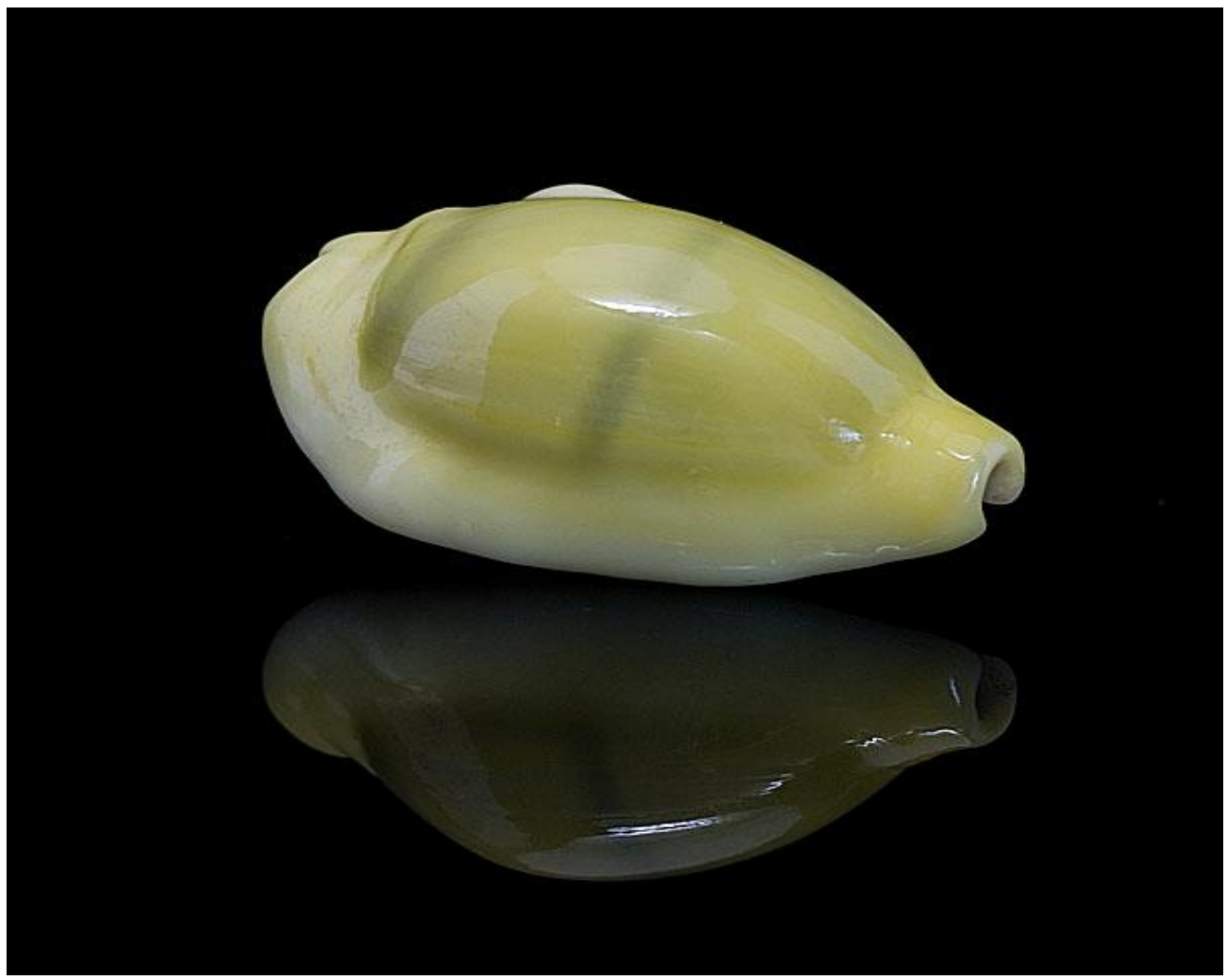

Picture 9. [C]. Monetaria moneta Linnaeus 1758 @ Phillip66 


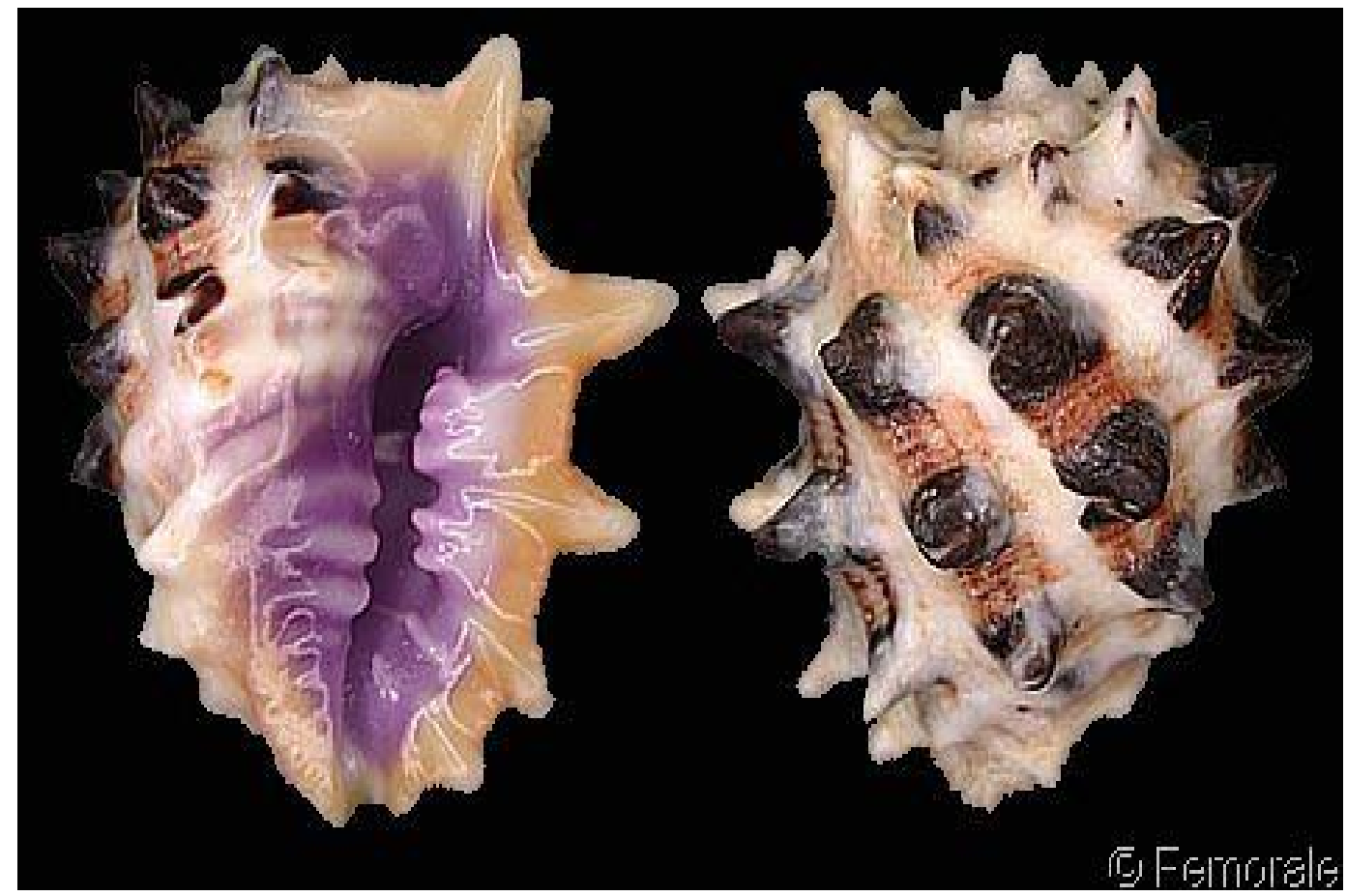

Picture 10. [D]. Drupa morum Röding, 1798 @ Femorale

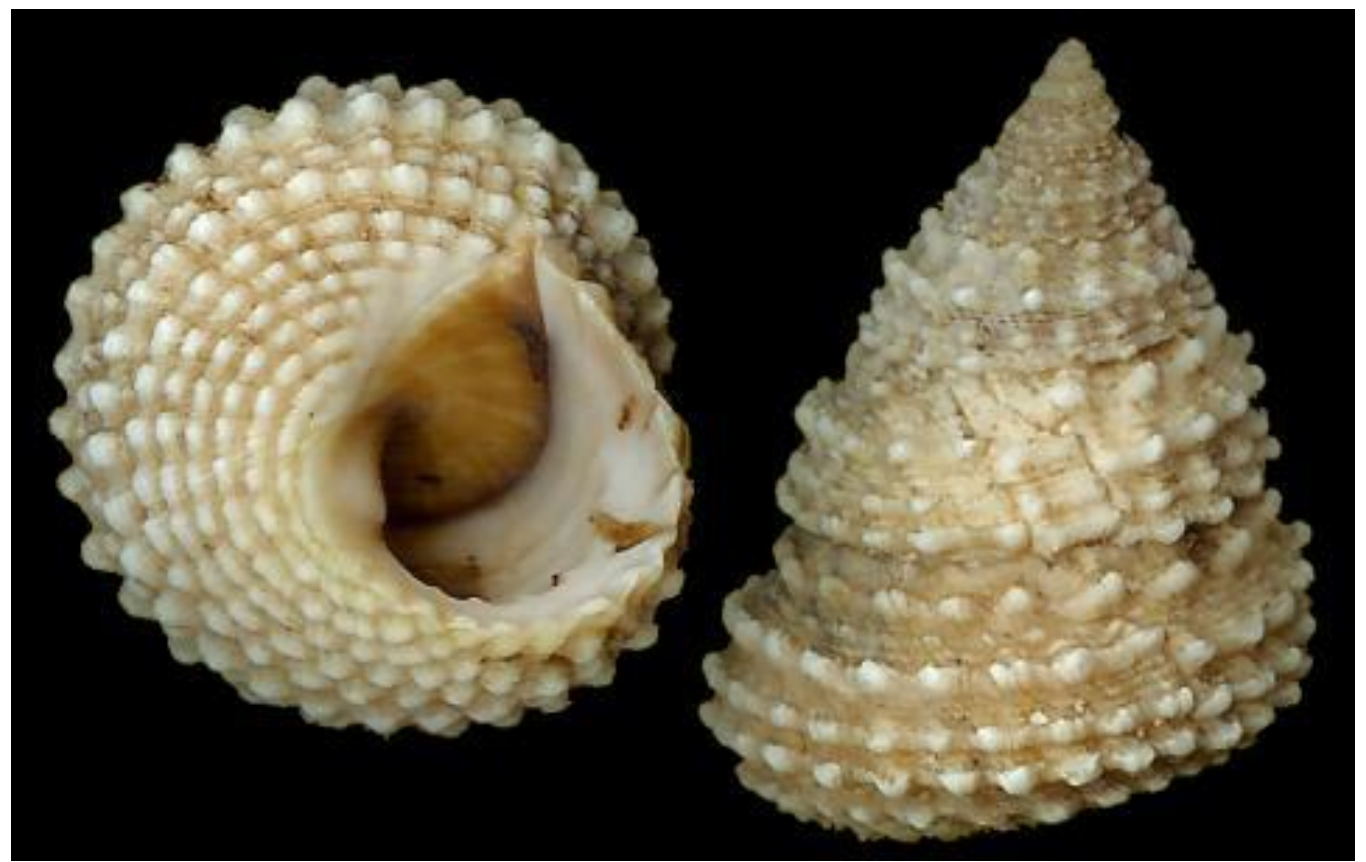

Picture 11. [D]. Tectarius grandinatus Gmelin, 1791 () Raymond Huet 


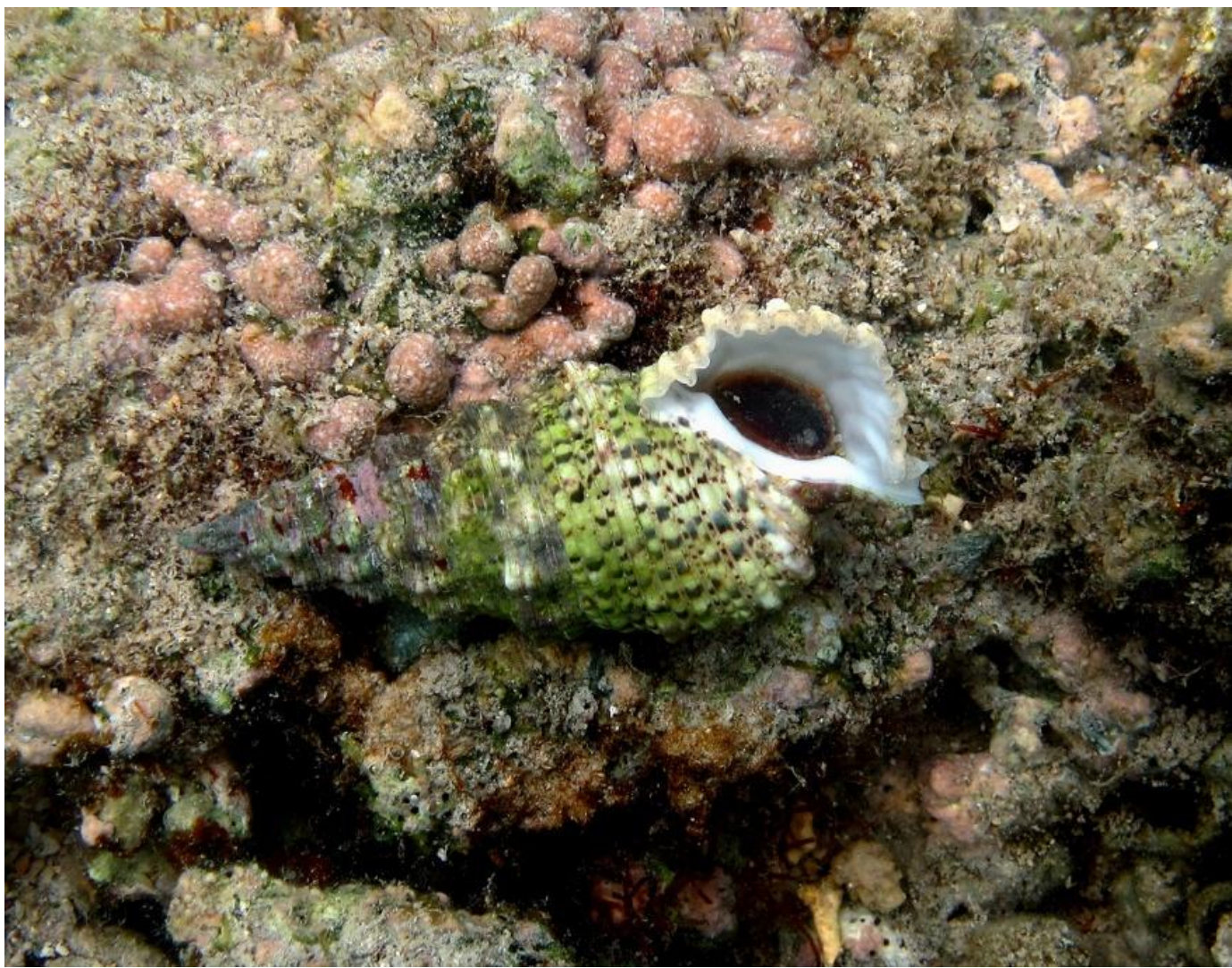

Picture 12. [D]. Cerithium echinatum Lamarck, 1822 @ Ph. Bourjon

(c) 2021 Béguinot; This is an Open Access article distributed under the terms of the Creative Commons Attribution License (http://creativecommons.org/licenses/by/4.0), which permits unrestricted use, distribution, and reproduction in any medium, provided the original work is properly cited.

Peer-review history:

The peer review history for this paper can be accessed here: http://www.sdiarticle4.com/review-history/66275 